\title{
Natural and synthetic carbohydrate- based vaccine adjuvants and their mechanisms of action
}

\author{
Carlo Pifferi (1) ${ }^{1}$, Roberto Fuentes (10 ${ }^{1}$ and Alberto Fernández-Tejada ${ }^{1,2 凶}$
}

Abstract | Modern subunit vaccines based on homogeneous antigens offer more precise targeting and improved safety compared with traditional whole-pathogen vaccines. However, they are also less immunogenic and require an adjuvant to increase the immunogenicity of the antigen and potentiate the immune response. Unfortunately, few adjuvants have sufficient potency and low enough toxicity for clinical use, highlighting the urgent need for new, potent and safe adjuvants. Notably, a number of natural and synthetic carbohydrate structures have been used as adjuvants in clinical trials, and two have recently been approved in human vaccines. However, naturally derived carbohydrate adjuvants are heterogeneous, difficult to obtain and, in some cases, unstable. In addition, their molecular mechanisms of action are generally not fully understood, partly owing to the lack of tools to elucidate their immune-potentiating effects, thus hampering the rational development of optimized adjuvants. To address these challenges, modification of the natural product structure using synthetic chemistry emerges as an attractive approach to develop well-defined, improved carbohydrate-containing adjuvants and chemical probes for mechanistic investigation. This Review describes selected examples of natural and synthetic carbohydrate-based adjuvants and their application in synthetic self-adjuvanting vaccines, while also discussing current understanding of their molecular mechanisms of action.

Adaptive (acquired) immunity

Evolved arm of the immune system mediated by B and T cells that acts specifically against targeted antigens to eliminate them, developing immunological memory for long-lasting protection.
${ }^{1}$ Chemical Immunology Lab, CIC bioGUNE, Basque Research and Technology Alliance (BRTA), Derio, Biscay, Spain.

2Ikerbasque, Basque Foundation for Science, Bilbao, Biscay, Spain.

凶e-mail: afernandeztejada@ cicbiogune.es

https://doi.org/10.1038/ s41570-020-00244-3
Advances in medicine, biotechnology and chemistry and recent insights into immunological mechanisms have enabled current vaccines to be rationally designed and endowed with pure, molecularly defined antigen substructures ${ }^{1}$. Compared with traditional whole-pathogen vaccines, these subunit vaccines offer advantages in terms of safety and precision, but they are less immunogenic and require the presence of adjuvants for optimal vaccine efficacy. Adjuvants are substances that enhance antigen-specific immune responses by triggering and modulating both the innate and adaptive (acquired) immunity ${ }^{2}$. They also allow the dose of expensive antigens to be limited, reduce booster immunizations, generate more rapid and durable immune responses, and increase the effectiveness of vaccines in poor responders.

Despite their key role, few sufficiently potent adjuvants with acceptable toxicity for human use are available in licensed vaccines. For more than 70 years, alum (a mixture of diverse aluminium salts) has been the only approved adjuvant in humans and is still one of the most popular in human vaccines. In late 2009, Adjuvant System 04 (AS04), a proprietary combination of alum and the Toll-like receptor 4 (TLR4) ligand monophosphoryl lipid A (MPLA), was approved for the vaccine against human papillomavirus (HPV), Cervarix. However, aluminium adjuvants have relatively low potency and elicit primarily an antibody-mediated T helper $2\left(\mathrm{~T}_{\mathrm{H}} 2\right)$-type immune response (BOX 1), with weak stimulation of cell-mediated immunity. Alum has been shown to act mainly as a delivery system that traps the antigen at the injection site by forming macromolecular aggregates, facilitating its slow release and uptake by antigen-presenting cells ${ }^{3}$. Nonetheless, the precise mechanism by which aluminium-containing adjuvants enhance the immune response remains poorly understood ${ }^{4}$. Apart from aluminium salts, the only other licensed adjuvants in human vaccines are oil-in-water emulsions containing squalene (MF59, AS03), in vitro-assembled influenza-virus-like particles (virosomes), and, most recently, the liposome-based Adjuvant System AS01 (REF.5). However, emulsion adjuvants have raised significant concerns owing to their adverse side effects ${ }^{6,7}$, and their molecular mechanisms of action are not fully defined ${ }^{8}$. AS01, a liposomal formulation containing MPLA and the saponin natural product QS-21, has only been recently approved for GSK's malaria (Mosquirix) and shingles (Shingrix) vaccines, 


\section{Box $1 \mid \mathbf{C D 4}^{+} \mathbf{T}$ helper cell subsets}

Naive $\mathrm{CD}^{+}{ }^{+} \mathrm{T}$ helper cells interact via their $\mathrm{T}$ cell receptors with peptide antigens presented on MHC class II molecules on the antigen-presenting cell surface. Among other factors ${ }^{282,283}$, activation and differentiation of effector $\mathrm{CD} 4^{+} \mathrm{T}$ helper cells into distinct subsets depends most predominantly on the nature of the innate immune signals that activated antigen-presenting cells upon antigen encounter, which generates a cytokine milieu that modulates the outcome of the adaptive immune response ${ }^{11,284}$.

The first subpopulations of effector $\mathrm{CD} 4^{+} \mathrm{T}$ helper cells discovered were the Thelper 1 $\left(T_{H} 1\right)$ and $T_{H} 2$ subsets ${ }^{285}$. These are responsible for controlling and eliminating intracellular and extracellular pathogens, respectively ${ }^{285}$. Adjuvants influence humoral and cellmediated immune responses by inducing $T_{H} 1$ and $T_{H} 2$ cells to produce $T_{H} 1$-associated or $T_{H}$ 2-associated cytokines, thus resulting in $T_{H} 1$ or $T_{H} 2$ immunity. $T_{H} 1$ differentiation is promoted by interferon- $\gamma$ (IFN $\gamma$ ) and interleukin-12 (IL-12) cytokines, leading to $T_{H} 1$ effector cells, which are best suited for eliminating intracellular pathogens. $\mathrm{T}_{\mathrm{H}} 1$ cells are characterized by producing IFN $\gamma$, a cytokine that activates macrophages, enhancing their microbial killing activity ${ }^{286}$, and that stimulates production of mouse $\lg \mathrm{G} 2 \mathrm{a} / \mathrm{lgG} 2 \mathrm{~b}$ and $\lg \mathrm{G} 3$ antibody subtypes, which are involved in opsonization and phagocytosis events $^{287}$. Moreover, IFN $\gamma$, together with IL-2, promotes differentiation of $C D 8^{+} \mathrm{T}$ lymphocytes into active cytotoxic T cells.

On the other hand, IL-4 induces the differentiation into $\mathrm{T}_{\mathrm{H}} 2$ effector cells, which are characterized by producing IL-4, IL- 5 and IL-13 cytokines $^{288}$, and are specialized in controlling infections by extracellular parasites. $\mathrm{T}_{\mathrm{H}} 2$ cytokines stimulate the production of high levels of $\lg M$ and non-complement fixing $\lg G$ isotypes, such as $\lg \mathrm{G} 1$ in mice ${ }^{287}$. Additionally, the $T_{H} 17$ effector cell subset originates from a cytokine milieu containing TGF $\beta$, IL- 6 and IL- 23 and is characterized by production of IL-17 and IL- 22 cytokines. $\mathrm{T}_{\mathrm{H}} 17$ cells are typically induced in response to extracellular bacteria and fungi and promote production of high-affinity $\lg G$ and $\lg A$ antibodies, which cooperate with neutrophils and macrophages at barrier tissue sites. Notably, $T$ follicular helper $\left(\mathrm{T}_{\mathrm{FH}}\right)$ lymphocytes are currently considered an activation state of a given effector cell subset, rather than a distinct lineage itself. Thus, $T_{F H}$ cells develop together with $T_{H} 1, T_{H} 2$ or $T_{H} 17$ cells to help B cells generate class-switched antibodies ${ }^{289}$. Finally, regulatory $T\left(T_{\text {reg }}\right)$ cells promote tolerance towards the recognized antigen, control the immune response and prevent autoimmunity ${ }^{200,291}$.

Cell-mediated immunity Involves activation of innate immune cells, T helper and antigen-specific cytotoxic $T$ cells, and release of cytokines in response to antigens to fight against infected or cancer cells.

Antigen-presenting cells Group of immune cells including dendritic cells, macrophages and B cells that mediate cellular responses by processing and presenting antigens on their surface for recognition by $T$ cells.

T helper $1\left(T_{H} 1\right)$ cells Subpopulation of $\mathrm{T}$ helper cells specialized in clearing viruses and bacteria that invade cells. $\mathrm{T}_{\mathrm{H}} 1$ cells are characterized by producing interferon- $\gamma$ and are associated with cellular immunity

T helper $2\left(\mathrm{~T}_{\mathrm{H}} 2\right)$ cells Specialized population of $T$ helper cells that regulate antibody-mediated immune responses against extracellular pathogens, such as parasites, by producing mainly interleukin-4 (IL-4), IL-5 and IL-13 cytokines. benefiting from a synergistic effect of both adjuvants in the early interferon- $\gamma$ (IFN $\gamma$ ) response that enhanced vaccine immunogenicity ${ }^{9,10}$.

Therefore, there is still a pressing need for novel, potent and less toxic adjuvants and new formulations for use in subunit vaccines. Classical adjuvant searches focused on improving the strength of the immune response by increasing antibody and/or cytokine production. Current efforts towards enhancing vaccine efficacy centre on the rational development of adjuvants that can elicit optimal, antigen-specific immune responses (responses associated with Thelper $1\left(T_{H} 1\right)$ cells or T helper $2\left(\mathrm{~T}_{\mathrm{H}} 2\right)$ cells, see BOX 1), including tailored antibody isotype profiles and $\mathrm{CD} 8^{+} \mathrm{T}$ cell responses ${ }^{11}$. To identify such adjuvants and select optimal adjuvantantigen combinations with defined immunological profiles and low toxicity, elucidating their precise pharmacological pathways and molecular mechanisms of action is essential. This mechanistic understanding will, in turn, enable the rational development of future vaccines against various human diseases.

Carbohydrates represent the most widespread class of biomolecules in nature. They play crucial roles in the immune system function and the stimulation of the immune response $\mathrm{e}^{12}$ that can be exploited by the chemistry community ${ }^{13}$. Carbohydrates possess many beneficial properties that make them promising adjuvant candidates, namely, high biocompatibility and tolerability and a strong safety profile ${ }^{14}$. A variety of natural carbohydrate structures, particularly MPLA and QS-21, have been clinically evaluated as adjuvants and are part of licensed Adjuvant Systems (AS) in human vaccines against HPV (AS04), herpes zoster and malaria (AS01). However, carbohydrate-based immunopotentiators obtained from natural sources are usually difficult to obtain in sufficient quantity, purity and homogeneity. Moreover, although the mechanisms of action of carbohydrate-based adjuvants have been extensively investigated, the molecular bases underlying the adjuvant activity of some of these compounds have not yet been fully elucidated. This is partly owing to the lack of tools to better explore its immune-potentiating effects. This, in turn, has hampered the rational design and development of optimized adjuvants and adjuvant combinations. Furthermore, the complexity and sensitivity of the diverse functionalities of the natural product structure limit the chemical derivatization of the parent compound, leaving limited opportunities for generation of synthetic analogues and structure-activity studies. By contrast, synthetic organic chemistry, including total synthesis and semi-synthetic strategies, offers a more attractive approach to molecularly defined, improved versions of carbohydrate-containing immunostimulants and chemical probes for mechanistic investigation, enabling structural modification of the corresponding natural products with a high level of chemical control.

This Review highlights recent advances in the development of carbohydrate-based adjuvants, including both naturally derived as well as rationally designed, chemically synthesized compounds, and discusses current understanding of the molecular mechanisms of action of the most promising natural and synthetic carbohydrate adjuvants. We focus primarily on adjuvants based on saponin, $\alpha$-galactosylceramide ( $\alpha$-GalCer), lipopolysaccharide (LPS) and zwitterionic polysaccharide. Polynucleotide (DNA/RNA)-based adjuvants are not discussed here because their immunomodulatory properties rely on the unmethylated cytosine-guanine (CpG) dinucleotides, rather than on the carbohydrate moiety.

\section{Saponin-based adjuvants}

Saponins are plant-derived natural products with a range of biological activities that consist of a lipophilic triterpenoid core flanked by one or more oligosaccharide chains (FIG. 1a). While the adjuvant activity of saponins has been widely investigated, including the recently identified Quillaja brasiliensis saponins ${ }^{15}$, the triterpene glycosides extracted from the bark of the Chilean tree Quillaja saponaria (i.e. QS) have been the primary focus for saponin-based adjuvant research since more than 30 years ago ${ }^{16}$. Purification by reverse-phase highperformance liquid chromatography (HPLC) of a heterogeneous, adjuvant-active, semi-purified bark extract (i.e. Quil-A) containing more than 20 water-soluble Q. saponaria saponins led to the identification of several QS saponin fractions that elicited humoral and cell-mediated responses, including QS-21, QS-18, QS-17 and QS-7 (REF. ${ }^{17}$ ) (FIG. 1a). The main saponin component, QS-18, was found to be highly toxic in mice but saponins QS-7 and QS-21 showed less toxicity. As QS-7 was less abundant, QS-21 was selected and has become 
Triterpene glycosides

Amphiphilic natural products

found in plants or marine

organisms comprising diverse

oligosaccharides covalently

linked to squalene-derived,

polycyclic $\mathrm{C}_{30}$ hydrocarbon

cores through $\mathrm{O}$-glycosidic

linkages. the most widely studied saponin adjuvant for the past 25 years $^{18}$.

QS-21 is not a single compound but a mixture of two isomeric saponins, QS-21-apiose (65\% abundance) and QS-21-xylose (35\% abundance), that share a glycosylated pseudo-dimeric acyl chain and a branched trisaccharide at the $\mathrm{C} 3$ position of the quillaic acid triterpene core, and differ in the terminal sugar of the linear tetrasaccharide that is linked to the $\mathrm{C} 28$ carboxyl group of the triterpene ${ }^{19}$ (FIG. 1a). QS-21 has been the preferred adjuvant in numerous vaccine clinical trials against a variety of cancers ${ }^{18}$ and infectious diseases ${ }^{20}$, and vaccine formulations containing QS-21 as an adjuvant have been recently licensed for human use ${ }^{5}$. QS-21 stimulates both antibody-based and cell-mediated immune responses, eliciting a $\mathrm{T}_{\mathrm{H}}$ 1-biased immune response ${ }^{21}$ with production of high titres of antibodies (IgG2a and IgG2b, in addition to IgG1), as well as antigen-specific cytotoxic T lymphocytes. However, except its recent approval as part of the AS01 system in GSK's malaria (Mosquirix) ${ }^{22}$ and shingles (Shingrix) ${ }^{23}$ vaccines, the inherent liabilities of QS-21, including scarcity, heterogeneity, hydrolytic instability and dose-limiting toxicity, have limited its clinical advancement as a stand-alone adjuvant.

\section{Structure-activity relationships of QS-21 and synthetic $Q S$ variants}

To address the inherent issues of QS-21 as an adjuvant and to gain insights into the structural features that are important for activity, a variety of semi-synthetic saponin variants have been developed, yielding important structure-activity relationships (SARs) within the QS saponin family.

One example is the chemical derivatization of the natural product to provide the semi-synthetic saponin adjuvant GPI-0100, which was prepared from QS bark extracts by saponification of the acyl chain, followed by amidation of the branched trisaccharide glucuronic acid with dodecylamine ${ }^{24}$. Whereas hydrolysis of the acyl chain resulted in deacylated saponins that did not stimulate $\mathrm{T}_{\mathrm{H}} 1$ immunity or cytotoxic $\mathrm{T}$ lymphocyte induction but, rather, $\mathrm{T}_{\mathrm{H}} 2$ immunity (significant IgG1 antibody levels but poor IgG2a/IgG2b responses) ${ }^{25}$, replacing the original acyl chain by the dodecylamide at the branched trisaccharide in GPI-0100 restored $\mathrm{T}_{\mathrm{H}} 1$ immunity and the ability to induce cytotoxic T lymphocyte responses ${ }^{26}$. Chemical synthesis of the presumably main immunoactive constituents of GPI-0100, based on QS-21 and QS-17/18, confirmed the adjuvant activity of the heterogeneous GPI-0100 adjuvant, albeit at doses five times higher than QS-21 itself ${ }^{27,28}$. To study further the acylation effect in saponin adjuvant activity, Wang et al. synthesized and immunologically evaluated two C28 pentasaccharide analogues of QS-7 with a single-sugar truncation and showed that acetylation at the 3-O and 4-O positions of the fucosyl unit (FIG. 1 b) shifted the immunostimulatory profile from the preferential production of IgG1 antibodies $\left(\mathrm{T}_{\mathrm{H}} 2\right.$-biased) to induction of both IgG1 and IgG2a antibody responses (mixed $\mathrm{T}_{\mathrm{H}} 1 / \mathrm{T}_{\mathrm{H}} 2$ immunity) ${ }^{29}$.

Synthetic chemistry represents a powerful strategy to obtain homogeneous, pure samples of saponin molecules and to develop new saponin analogues with improved properties and therapeutic profiles. Pioneering work by Gin and colleagues led to the first total syntheses of QS-2 $1_{\text {Api }}\left(\right.$ REFS $\left.^{30,31}\right)$, QS-2 $1_{\text {Xyl }}\left(\right.$ REF. $\left.^{32}\right)$ and QS-7 ${ }_{\text {Api }}\left(\right.$ REF. $\left.^{33}\right)$, and to the development of a semi-synthetic sequence ${ }^{34}$ to a range of chemically stable, amide-containing acyl chain variants of QS-21 (REF. ${ }^{35}$ ). These enabled detailed SAR studies of this complex molecule, defining minimal structural requirements for adjuvant activity ${ }^{36}$ (FIG. 1a).

Strikingly, the terminal sugar within the linear tetrasaccharide ${ }^{37}$ and the entire branched trisaccharide turned out to be dispensable for adjuvant activity ${ }^{38}$. Simplification of the acyl chain backbone and modification at the acyl chain terminus did not impair activity $^{35}$, with the exception of a terminal amino group that abolished adjuvant activity ${ }^{37}$. Conjugation of the aldehyde-containing immunopotentiator tucaresol at this terminal amine restored activity, although a synergistic enhancement was not observed ${ }^{39}$. The central glycosidic linkage was quite sensitive to chemical modification, and subtle central linker variations led to QS analogues with drastically different activities that correlated with specific conformational preferences ${ }^{40}$.

The triterpene C4-aldehyde substituent, hypothesized to play a role in the ability of QS-21 to induce $\mathrm{T}_{\mathrm{H}} 1$ immunity, was not required for adjuvant activity in truncated synthetic saponins as assessed in terms of antibody response in mice, while the $\mathrm{C} 16$-alcohol enhanced activity with higher IgG production ${ }^{38}$. Subsequently, our multidisciplinary studies involving immunological evaluation and conformational analysis of branched trisaccharide truncated synthetic saponins with targeted modifications at the triterpene have underlined the dispensability of the C4-aldehyde and identified a key role for the C16-hydroxyl group in saponin conformation that correlated with adjuvant activity ${ }^{41}$, highlighting echinocystic acid as a valuable triterpene source for potent saponin adjuvants further emphasized by its greater affordability and sustainability. Overall, these SAR studies have provided improved, synthetically accessible QS saponins with potent adjuvant activity and non-toxicity in mice, and have enabled the development of saponin probes to gain early insights into their mechanisms of action (see below) ${ }^{42}$. Most recently, Wang and colleagues have shown that stepwise truncation of the C28 hexasaccharide of QS-7 to a tetrasaccharide retained its ability to induce IgG1 and IgG2a antibodies ( $\mathrm{T}_{\mathrm{H}} 1$ response), albeit at levels lower than the pentasaccharide analogue and QS-21, whereas further sugar truncation led to progressively decreased adjuvant activity, with only the $\mathrm{C} 28$ trisaccharide variant inducing significant IgG1 $\left(\mathrm{T}_{\mathrm{H}} 2\right)$ antibody response $\mathrm{e}^{43}$ (FIG. $\left.1 \mathrm{~b}\right)$.

\section{Mechanisms of action}

The mechanisms of action of QS-21 are poorly understood, hindering rational development of improved analogues and selection of optimal adjuvant-antigen combinations in future vaccines. A depot effect by which the adjuvant increases the lifetime of the antigen and its presentation to the immune system may not be operative, as prolonged persistence and sustained released of the antigen at the injection site could not be 


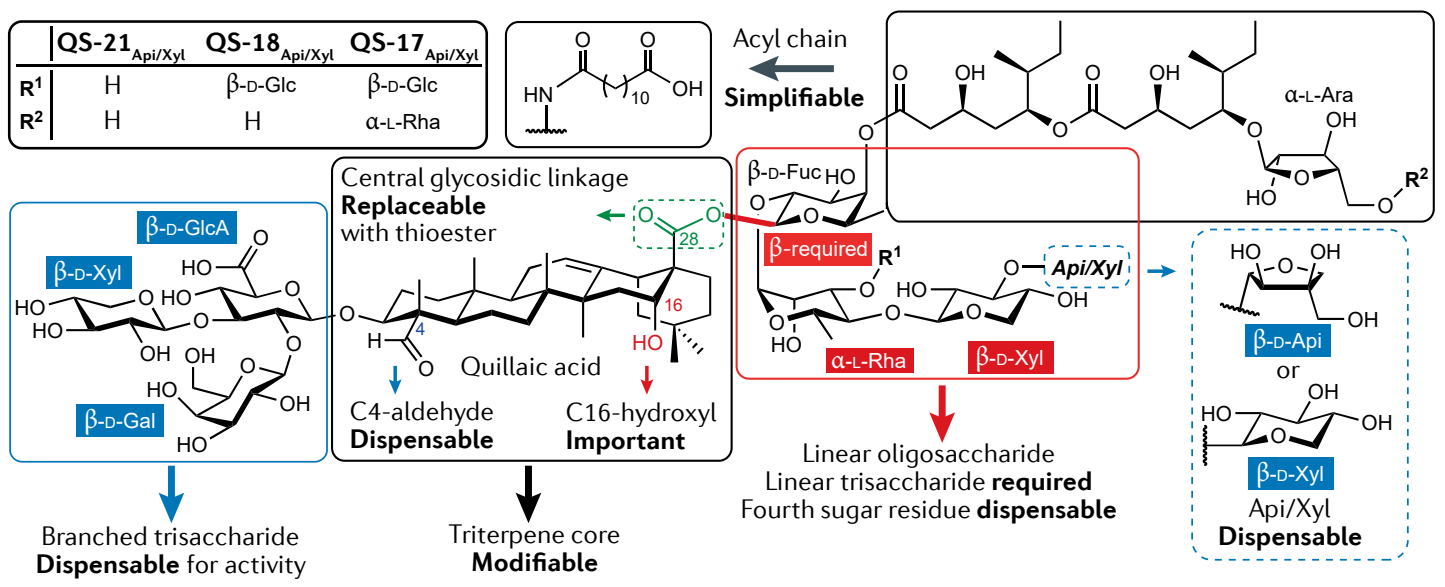

b

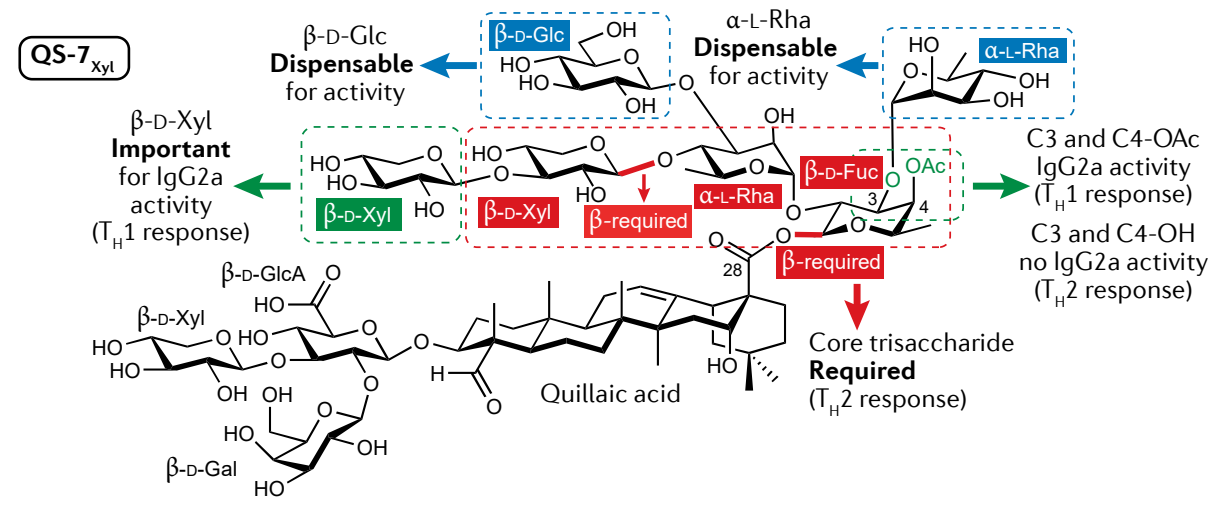

C

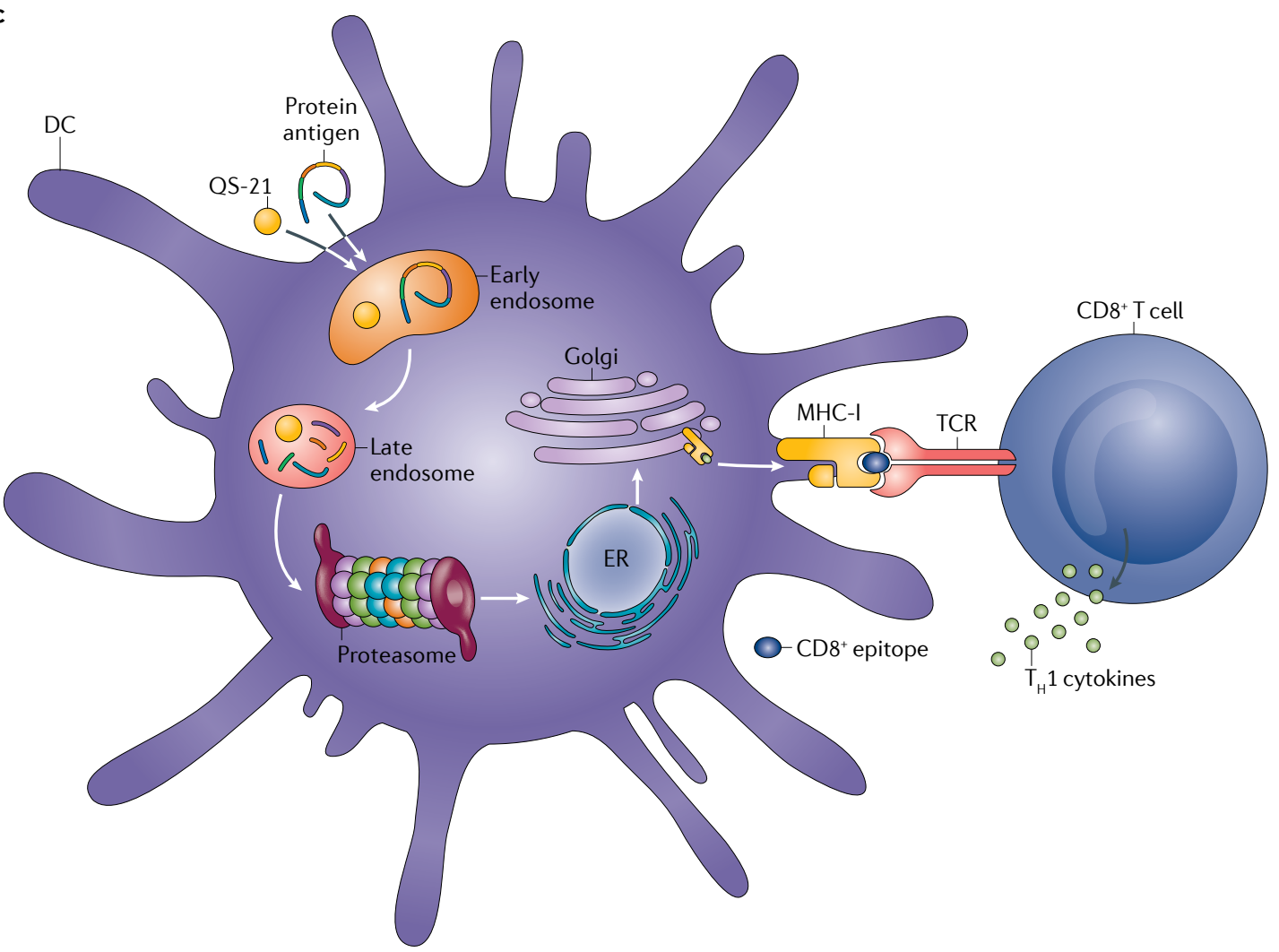


4 Fig. 1 | Structures of natural and synthetic QS-based saponin adjuvants and proposed mechanism of action for QS-21-related saponin adjuvants. a | Structures of saponin natural product adjuvants QS-21, QS-18 and QS-17 derived from the Quillaja saponaria tree ${ }^{17}$ and summary of structure-adjuvant activity relationships of QS-21 (REF. $\left.{ }^{36}\right)$. b | Structures of saponin natural product adjuvant QS-7 xyl $\left(\right.$ REF. $\left.^{17}\right)$ and summary of QS-7 structure-adjuvant activity relationships ${ }^{29,43}$. $\mathbf{c}$ Schematic representation of the proposed mechanism of action for QS-21-related saponin adjuvants ${ }^{48}$. Upon endocytosis, exogenous protein antigens and QS-21 are delivered to dendritic cells (DCs). Following QS-21mediated disruption of the endosomal membrane, cleaved protein antigens can be further processed into smaller peptide fragments in the cytosol by the proteasome machinery. Degraded peptides are translocated into the endoplasmic reticulum (ER) by transporter molecules, where chaperones facilitate their binding to newly synthesized MHC class I (MHC-I) molecules for vesicular migration through the Golgi to the cell surface. Finally, peptide epitopes exposed on the DC surface in association with MHC-I molecules are presented to naive $\mathrm{CD} 8^{+} \mathrm{T}$ cells (cross-presentation) through the T cell receptor (TCR).

$\mathrm{T}_{\mathrm{H}}$, Thelper. Part c adapted from REF. ${ }^{47}$, CC BY 4.0 (https://creativecommons.org/licenses/ by/4.0/), and with permission from REF. ${ }^{53}$, Elsevier.

\section{Caspase \\ Caspases are a family of \\ cysteine protease enzymes that play important roles in various cellular processes, including apoptosis and inflammation. Inflammatory caspases are involved in inflammatory cytokine signalling.}

\section{Lysosomes}

Subcellular organelles

responsible for degrading proteins and other internalized material. Maturation of endosomes and fusion into lysosomes creates an acidic environment optimal for lysosomal acid hydrolases.

Pro-inflammatory cytokines Small proteins secreted by immune cells (e.g. interleukin-1, tumour necrosis factor, interferon- $\gamma$ ) in response to danger signals or non-self stimuli as signalling molecules and immune mediators promoting inflammatory responses to infection.

\section{Lipid bodies}

Functionally active cellular organelles comprising a neutral lipid core surrounded by a phospholipid monolayer. Lipid bodies sequester lipid and proteins, modulating signalling pathways and inflammatory responses.

\section{Inflammasome}

Multiprotein intracellular

complex of the innate immune system that activates

pro-inflammatory cytokines interleukin-1 $\beta$ (IL-1 $\beta)$ and

IL-1 8 in response to microbial infection and cellular damage. correlated with saponin adjuvant activity ${ }^{21}$. Binding to TLR2 and TLR4 has also been excluded ${ }^{44}$. QS-21 has been hypothesized to interact with cell surface lectins through its carbohydrate residues, facilitating antigen uptake into antigen-presenting cells, and to bind amino groups on $\mathrm{T}$ cell receptors via imine formation through its triterpene aldehyde, delivering a co-stimulatory signal required for $\mathrm{T}$ cell activation and $\mathrm{T}_{\mathrm{H}} 1$ cellular immunity ${ }^{45}$.

A number of studies have investigated the mechanisms of action of QS-21 formulated in liposomes and/or in combination with MPLA. In a liposomal formulation injected intramuscularly, QS-21 targeted subcapsular macrophages in the draining lymph nodes, leading to multiple effects: activation of a caspase (i.e. caspase 1), subsequent recruitment and activation of neutrophils and dendritic cells, and, ultimately, induction of antibody and cellular responses, all dependent on myeloid differentiation factor 88 (MyD88), a key signal transduction adapter for interleukin-1 (IL-1)/ IL-18 receptors ${ }^{46}$. A proposed model based on recent data with QS-21 formulated in liposomes involves cholesterol-dependent endocytosis of QS-21 by human monocyte-derived dendritic cells (moDCs), followed by accumulation in and destabilization of the lysosomes. This lysosomal disruption can induce cathepsin B and SYK kinase-mediated activation of moDCs and production of pro-inflammatory cytokines, and could also influence antigen processing and translocation to the cytosol for subsequent cross-presentation ${ }^{47,48}$ (FIG. 1 C). Specifically, saponin-based adjuvants, alone in purified form or formulated with cholesterol and phospholipids in 40-nm cage-like structures (ISCOMATRIX) have been shown to increase antigen cross-presentation in moDCs via endosomal escape and formation of intracellular lipid bodies ${ }^{49}$. Mechanistically, ISCOMATRIX relies mostly on Quillaja saponins' adjuvant abilities to (1) induce pro-inflammatory cytokines/chemokines that recruit and activate antigen-presenting cells (dendritic cells), (2) promote antigen trafficking and release into the cytosol and (3) link the innate and adaptive immune responses in vivo in a TLR-independent but MyD88-dependent manner ${ }^{50}$. In addition to MyD88, NLRP3 inflammasome-related and inflammasome-unrelated IL-18 production/IL-18R signalling modulated innate and adaptive cellular immunity to an ISCOMATRIX vaccine $^{51}$.

When co-administered with MPLA in mouse antigenpresenting cells, QS-21 was identified as an NLRP3 inflammasome activator, inducing caspase 1-dependent IL- $1 \beta /$ IL-18 production; however, this signalling pathway may inhibit the adjuvant effects of QS-21 in vivo ${ }^{52}$.

Integrating the previous mechanistic insights, a dual mechanism of action has been recently proposed, whereby QS-21 would act on both T cells and antigen-presenting cells (i.e. dendritic cells) in receptor-mediated and non-receptor-mediated manners, respectively ${ }^{53}$. According to this model, the triterpene aldehyde group reacts with $\varepsilon$-amino groups, likely from the $\mathrm{CD} 2$ receptor on $\mathrm{T}$ cells, forming an imine that provides $\mathrm{T}$ cells with a co-stimulatory signal required for $\mathrm{T}$ cell activation and $\mathrm{T}_{\mathrm{H}} 1$ immunity ${ }^{45}$. The proposed mechanism on dendritic cells involves cholesterol-mediated internalization of QS-21 (and exogenous antigens) by interaction with its triterpene and acyl chain, followed by lysosomal destabilization. This leads to dendritic cell activation and pro-inflammatory cytokine production, as well as antigen release to the cytosol for further processing and antigen cross-presentation to CD8 T cells, promoting cytotoxic T lymphocyte responses (FIG. 1c).

Moreover, QS-21-based chemical probes, including radiolabelled and fluorescent synthetic variants, have been utilized in in vivo biodistribution and fluorescence imaging studies to investigate their mechanisms of action. Adjuvant-active saponin probes (co-administered with ovalbumin (OVA) as a prototypic antigen) localized at the injection site and in the draining lymph nodes preferentially over structurally related inactive/attenuated congeners, and the most active fluorescein-labelled saponin was internalized into dendritic cells ${ }^{38}$. These studies suggest a role for adjuvant-active QS variants in the trafficking of OVA by antigen-presenting cells to the draining lymph nodes, and set the stage for additional investigations with related saponin probes that are ongoing in our group to elucidate the molecular mechanisms of these synthetic saponin adjuvants.

Nonetheless, the variety of structurally distinct saponin adjuvants, some of them devoid of the C4-aldehyde, and the lack of adjuvant activity of other saponin families makes it unlikely that a single, universal mechanism could be operative for QS-21, related synthetic variants and other non-QS saponin adjuvant ${ }^{53}$. In any case, the identification of the cellular receptor responsible for interaction with aldehyde-containing saponins via imine formation with the $\mathrm{C} 4$-aldehyde substituent would provide solid experimental evidence for the suggested role of this group in saponin adjuvant activity, as well as for the proposed mechanism of action of QS-21. The fact that conservative structural modifications and key functionalities such as the aldehyde and hydroxyl groups have such an impact on saponin immunopotentiation hints at mechanisms of action that may only be applicable to closely related saponins with sufficient structural similarity. The established correlation between three-dimensional structure and adjuvant activity 


\section{iNKT cells}

Subpopulation of innate-like T cells (natural killer T cells) expressing limited $\mathrm{T}$ cell receptor $\alpha \beta$ chains that regulate diverse immune responses via rapid, massive inflammatory cytokine release upon $\alpha$-galactosylceramide CD1d activation. implies that saponin conformation is vital for activity and may contribute to proper biodistribution, subcellular localization and/or target binding. This feature, together with the pronounced SAR within this saponin class, suggests a mechanism of action involving interaction with currently unknown (macro)molecular targets.

\section{a-Galactosylceramide-derived adjuvants}

a-GalCer (KRN7000) is a marine-sponge-derived synthetic glycolipid with antitumour and immunostimulatory properties. Structurally, it contains a galactose attached through an $\alpha$-O-glycosidic linkage to a
C18 phytosphingosine with an amide-linked, saturated C26 fatty acyl chain ${ }^{54}$ (FIG. 2a). It binds to the non-polymorphic MHC class I (MHC-I)-like antigenpresenting molecule CD1d on dendritic cells, with its hydrophobic alkyl chains buried inside the CD1d binding groove and its polar portion at the CD1 surface, exposed to the solvent for recognition by the $\mathrm{T}$ cell receptor, in an orientation that is determined by conserved polar contacts with defined CD1d residues ${ }^{55}$. Presentation of $\alpha$-GalCer bound to CD1d on dendritic cells to the $\mathrm{T}$ cell receptor on invariant natural killer $\mathrm{T}$ cells (iNKT cells, an unconventional type of T cell lymphocyte expressing a semi-invariant $\alpha \beta \mathrm{T}$ cell receptor

a

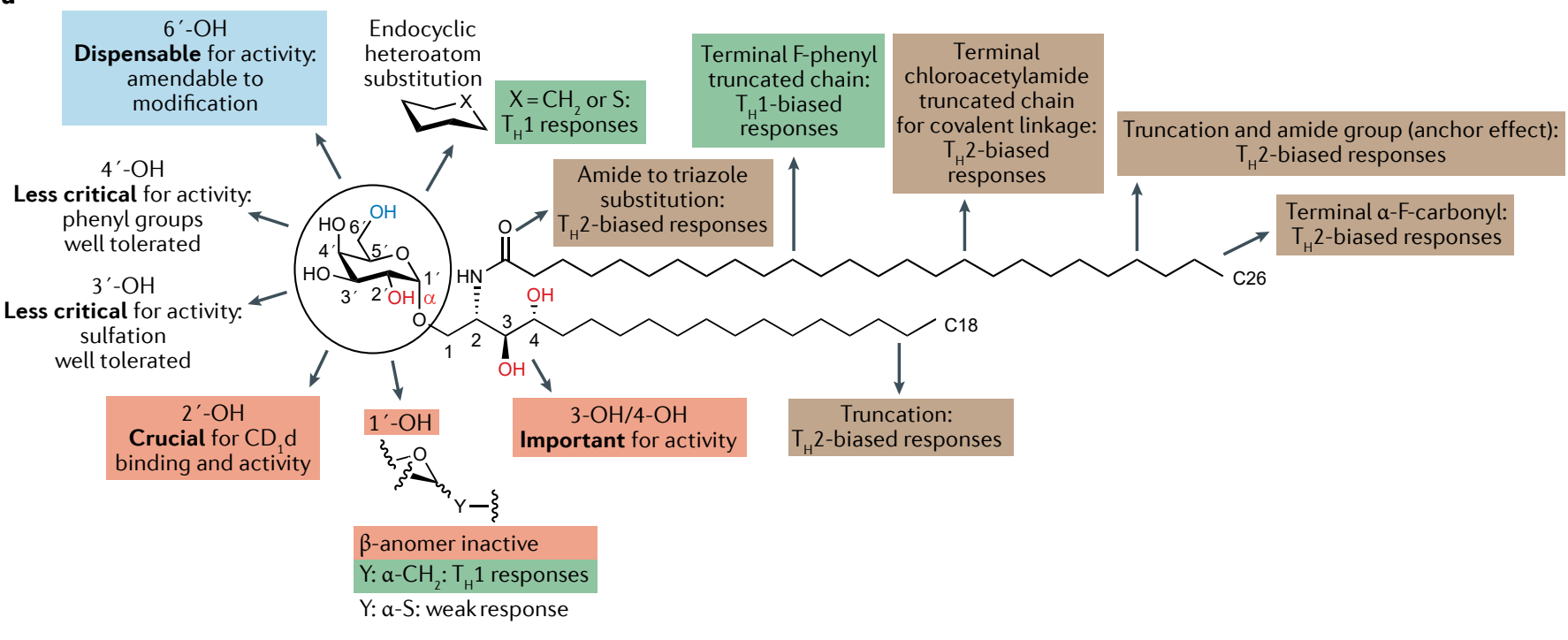

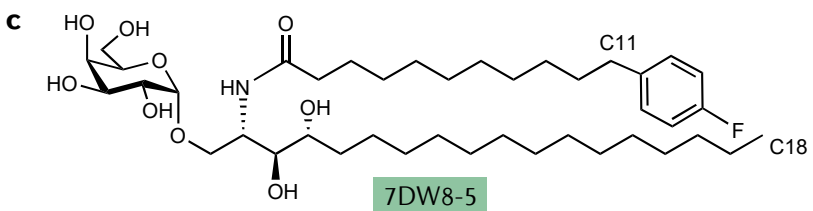

\section{d}
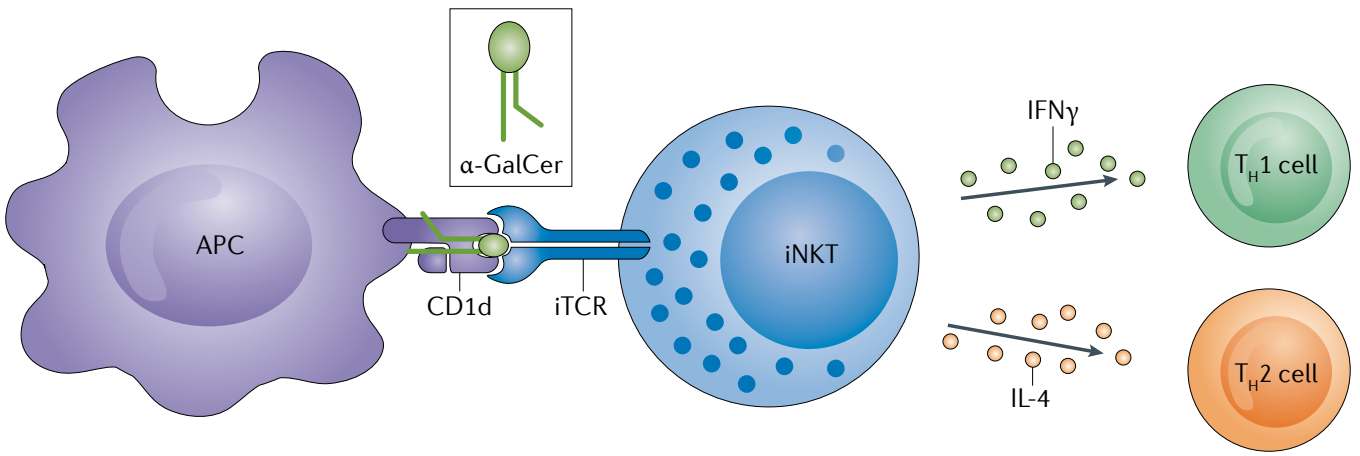

Fig. 2 | Structures of natural and synthetic $\alpha$-GalCer-based adjuvants and mechanism of action of $\boldsymbol{\alpha}$-GalCer. a | Structure of natural $\alpha$-galactosylceramide ( $\alpha$-GalCer) and key structural modifications and their impact on activity and cytokine profile production ${ }^{60}$. b,c $\mid$ Structures of synthetic $a-G a l C e r v a r i a n t s$ inducing Thelper $2\left(T_{H} 2\right)$-biased $(\mathrm{OCH} \text {, panel b })^{87}$ and $\mathrm{T}_{\mathrm{H}} 1$-biased (7DW8-5, panel c c ${ }^{96}$ responses. $\mathbf{d} \mid$ Schematic representation of invariant natural killer T (iNKT) cell activation and $\alpha-G a l C e r$ mechanism of action $^{120} \cdot \alpha$-GalCer presentation on antigen-presenting cell (APC) surface in association with CD1d enables activation of iNKT cells by interaction with their invariant T cell receptor (iTCR). iNKT cells rapidly secrete both pro-inflammatory $\left(\mathrm{T}_{\mathrm{H}} 1\right)$ and anti-inflammatory $\left(\mathrm{T}_{\mathrm{H}} 2\right)$ cytokines, such as interferon- $\gamma$ (IFN $\gamma$ ) and interleukin-4 (IL-4), respectively. Depending on several factors, including the nature of the glycolipid antigen, its loading mode into CD1d protein, cytokine milieu, cell types that present the glycolipid antigen, co-stimulatory interactions and frequency of treatment, activated iNKT cells can exhibit a diverse range of responses on other cell types, such as B and T lymphocytes, macrophages, dendritic cells and NK cells. Part d adapted with permission from REF. ${ }^{60}$, ACS, from REF. ${ }^{63}$, CC BY 4.0 (https://creativecommons.org/licenses/by/4.0/), and with permission from REF. ${ }^{120}$, Future Medicine. 
restricted to CD1d and characterized by an invariant a-chain ${ }^{56}$ ) leads to iNKT cell activation. While iNKT cells only comprise a small fraction of the overall T cells in the human bloodstream, they represent a special population of lymphocytes owing to their ability to provide rapid response. Thus, these activated iNKT cells immediately produce $\mathrm{T}_{\mathrm{H}}$ 1-type $(\mathrm{IFN} \gamma)$ and $\mathrm{T}_{\mathrm{H}}$ 2-type (IL-4) cytokines upon antigen presentation, stimulating innate and adaptive immune responses ${ }^{57}$. This unconventional population, characterized by the lack of recognition of classical peptide antigens, limited $\mathrm{T}$ cell receptor diversity and scarce abundance, has been shown to induce potent effects and responses through different mechanisms and effector functions. iNKT cells provide new opportunities for T cell immunotherapy, and for the development of defined chemical targets to impact iNKT cell activation and enhance adaptive immune responses in an adjuvant-like fashion ${ }^{58}$.

\section{Structure-activity relationships and synthetic $\alpha$-GalCer variants}

Despite the therapeutic potential of $\alpha-G a l C e r$, the conflicting activities of the elicited $\mathrm{T}_{\mathrm{H}} 1$ and $\mathrm{T}_{\mathrm{H}} 2$ cytokines have limited its clinical efficacy ${ }^{59}$. This has driven the development of synthetic analogues that can influence NKT cell-dendritic cell interactions and stimulate preferential expression of $\mathrm{T}_{\mathrm{H}} 1$ or $\mathrm{T}_{\mathrm{H}} 2$ cytokines by incorporating defined chemical modifications at the galactose and lipid moieties ${ }^{60}$ (FIG. 2a), guided by the crystal structure of CD1d- $\alpha-G a l C e{ }^{61}$ and the NKT T cell receptor-CD1d- $\alpha-\mathrm{GalCer}^{62}$.

The synthesis and evaluation of these derivatives has enabled accurate SAR studies, identifying key structural features required for $\mathrm{T}_{\mathrm{H}} 1$-biased and $\mathrm{T}_{\mathrm{H}}$ 2-biased responses (FIG. 2a) and more potent and $\mathrm{T}_{\mathrm{H}}$-selective $\alpha$-GalCer variants (FIG. 2b,c) for use as vaccine adjuvants ${ }^{63}$.

Early modifications at the sugar moiety revealed that the pyranose form and especially the $a$-anomeric configuration are essential for adjuvant activity ${ }^{57}$. Moreover, $\alpha$-D-fucose (Fuc) and, to a lesser extent, $\alpha$-glucose, but not $\alpha$-mannose-linked ceramides, were found to stimulate iNKT cells, with $\alpha$-GlcCer being less active. These results suggest the importance of the galactose $4^{\prime}-\mathrm{OH}$ and especially the $2^{\prime}-\mathrm{OH}$ in immunostimulation, while the $6^{\prime}-\mathrm{OH}$ is dispensable for activity ${ }^{63}$. As key positions involved in the interaction with the $\mathrm{T}$ cell receptor and in the stability of the CD1d-glycolipid-T cell receptor complex, modifications at the $4^{\prime}, 3^{\prime}$ and especially $2^{\prime}$ positions (e.g. $\mathrm{H}$ (deoxy), $\mathrm{F}, \mathrm{N}_{3}, \mathrm{NH}_{2}$, NHAc, OMe, $\mathrm{O}\left(\mathrm{CH}_{2}\right)_{2} \mathrm{OH}=4^{\prime}-\mathrm{O}$-methyl or $4^{\prime}$ - $\mathrm{O}$-ethanol- $\alpha$-GalCer $)$ led to reduced bioactivity ${ }^{64,65}$ (FIG. 2a). Notable exceptions were the 3-O-sulfo- $\alpha$-GalCer ${ }^{66,67}$ and the $4-O$ phenylpropyl- $\alpha$-GalCer analogues ${ }^{68}$, which induced comparable $\mathrm{T}_{\mathrm{H}} 1 / \mathrm{T}_{\mathrm{H}} 2$ responses, as well as benzylmodified 4- $O$ variants that promoted $\mathrm{T}_{\mathrm{H}} 1$-biased immunity ${ }^{69,70}$. Thus, while deletion or modifications at the 2 position abolished activity, particular variations at the 3-OH (sulfation) and especially the 4-OH (phenyl groups) were less critical for immunostimulation (FIG. 2a).

In contrast to the secondary hydroxyl groups, the galactose $6^{\prime}-\mathrm{OH}$ is not involved in $\mathrm{H}$-bond formation within the CD1d- $\alpha-$ GalCer-T cell receptor complex.
Therefore, modifications of the sugar moiety have mainly focused on this position. In addition to the $\mathrm{T}_{\mathrm{H}} 1 / \mathrm{T}_{\mathrm{H}} 2$-inducing $6^{\prime}$ - deoxy analogue $(\alpha \text {-FucCer })^{71}$, potent $\mathrm{T}_{\mathrm{H}} 1$-biasing variants of $\alpha$-GalCer included C6-substituted amides, ureas ${ }^{72}$ and carbamates, such as NU- $\alpha$-GalCer and PyrC- $\alpha-G a l C e r$, which showed promising antitumour activity in mice ${ }^{73,74}$.

A variety of other groups have been attached at the C6' position. These included monosaccharides, for example, the immunologically active $\alpha$-Gal $(1 \rightarrow 6) \alpha$-GalCer analogue $\mathrm{e}^{75}$, amino acids attached through a triazole linker to provide variants (Lys- $\alpha-\mathrm{GalCer}$ ) that exhibited good selectivity for $\mathrm{T}_{\mathrm{H}} 1$ responses $^{76}$, as well as biotin and small fluorophores ${ }^{77,78}$, yielding immunostimulatory-active analogues for further mechanistic investigation.

Among the diverse galactose-modified analogues, including the more stable and strongly $\mathrm{T}_{\mathrm{H}} 1$-inducing a-carba-GalCer variant in which the endocyclic oxygen is replaced by a carbon ${ }^{79}$ (FIG. 2a), only a few elicited modest $\mathrm{T}_{\mathrm{H}} 2$ profiles, namely, 6-triazole-substituted derivatives $^{80}$ and 6 -O-alkylated analogues bearing long ether-linked aliphatic chains ${ }^{81}$.

Substitution of the exocyclic glycosidic oxygen by a methylene unit provided the more stable $\mathrm{C}$-glycoside analogue ( $\alpha$-C-GalCer) (FIG. 2a), which exhibited a marked $\mathrm{T}_{\mathrm{H}} 1$ response (IFN $\gamma$ and IL-12 cytokines) and superior antimalaria and antimetastatic activity in mice ${ }^{82}$, but was inactive in human cells ${ }^{83}$. The thioglycoside analogue $\alpha$-S-GalCer was also synthesized ${ }^{84}$, showing no bioactivity in mice, while inducing a $\mathrm{T}_{\mathrm{H}} 1$ profile in humans ${ }^{85}$.

A variety of $\alpha$-GalCer analogues with diverse structural modifications in the lipid moiety have also been synthesized, enabling further SAR studies (FIC. 2a). Selective $\mathrm{T}_{\mathrm{H}}$ 2-inducing analogues were obtained by truncation of the fatty acyl and/or phytosphingosine chains ${ }^{86}$ and by incorporation of double bonds into the fatty acyl chain, such as the OCH (REF. ${ }^{87}$ ) (FIG. 2b) and $\alpha-$ GalCerC20:2 analogues, respectively ${ }^{88}$. Additional acyl chain modifications that yielded strong $\mathrm{T}_{\mathrm{H}}$ 2-biased cytokine responses included (1) bioisosteric replacement of the acyl chain amide with a triazole, especially in long-chain ana$\operatorname{logues}^{89},(2)$ incorporation of an amide in short fatty acid chain derivatives for hydrogen bonding with polar residues in the CD1d pocket ('anchoring effect') ${ }^{90,91}$, (3) incorporation of $\alpha$-fluorocarbonyl moiety at the acyl chain terminus ${ }^{92}$ and (4) introduction of a polar chloroacetylamide terminal group in short acyl chain analogues for covalent linkage with CD1d pocket residues ${ }^{93}$ (FIG. 2a).

Based on activity and structure studies ${ }^{94}$, introduction of an aromatic group at the fatty acyl chain terminus led to potent $\mathrm{T}_{\mathrm{H}} 1$ cytokine (IFN $\gamma$ ) secretion ${ }^{95}$ (FIG. 2a). For example, the fluorophenyl $\mathrm{C} 10$ fatty acid derivative 7DW8-5 (REF. ${ }^{96}$ ) (FIG. 2c) showed stronger adjuvant activity than $\alpha-G a l C e r$ in HIV, malaria and influenza vaccines ${ }^{97}$, while the 4-(4-fluorophenoxy) phenyl undecanoyl analogue (C34) offered superior protective antibacterial and antiviral efficacies ${ }^{98}$ and more potent adjuvant activity with a Globo-H conjugate cancer vaccine ${ }^{99}$.

Chemical modifications on the phytosphingosine polar portion (e.g. H (deoxy), F) revealed that both the 
4- $\mathrm{OH}$ and especially the 3-OH are important for NKT cell activation ${ }^{100-104}$ (FIG. 2a). A doubly modified $\alpha$-GalCer variant combining a 4-deoxy-phytosphingosine chain with a hydrocinnamoyl ester on the galactose $\mathrm{C6}^{\prime}-\mathrm{OH}$ (AH10-7) induced strong $\mathrm{T}_{\mathrm{H}} 1$ bias and antitumour iNKT cell responses in mice ${ }^{105}$, while synthetic diethercontaining acyl chain analogues promoted selective $\mathrm{T}_{\mathrm{H}} 17$ cell responses (IL-17) in vitro ${ }^{106}$. More recently, a potent photoswitchable analogue incorporating an azobenzene within the acyl chain was developed, which enhanced $\mathrm{T}_{\mathrm{H}} 1 / \mathrm{T}_{\mathrm{H}} 2$ cytokine production upon ultraviolet irradiation $^{107}$.

Moreover, analogues bearing biotin, NBD fluorophore (NBD- $\alpha$-GalCer) and benzophenone at the acyl chain terminus were developed to investigate CD1d distribution and glycolipid presentation in dendritic cells, with the latter two showing superior immunostimulatory activity to $a-G a l C e r$ itself $^{108-110}$.

\section{Synthetic self-adjuvanting vaccines}

Based on the SAR above, $\alpha$-GalCer variants have been covalently attached to carbohydrate and peptide epitopes to generate synthetic 'self-adjuvanting' vaccines incorporating the adjuvant and antigen components in the same molecule.

Cavallari et al. conjugated the Streptococcus pneumoniae capsule polysaccharide CPS4 to the galactose $\mathrm{C}^{\prime}-\mathrm{OH}$ of $\alpha$-GalCer, elongated with an amino linker, yielding a carbohydrate-lipid vaccine that induced CPS-specific memory B cells and high-affinity IgG antibodies protective against pneumococcal infection in mice ${ }^{111}$. Several carbohydrate-based cancer vaccine candidates have been synthesized by attaching tumour-associated threonine-linked Tn ( $\alpha$-GalNAc-O-Thr $)^{112}$ and sialyl Tn (Neu5Ac $(\alpha 2 \rightarrow 6) \alpha-$ GalNAc) $(\mathrm{STn})^{113}$ antigens to the galactose $\mathrm{C} 6$ position via amide linkages, providing conjugates that, upon liposomal formulation, elicited strong antigen-specific $\mathrm{T}_{\mathrm{H}} 1$-type/ $\mathrm{T}_{\mathrm{H}} 2$-type IgG antibodies in mice. Most recently, $\mathrm{Li}$ and colleagues prepared a C6'-azido a-GalCer variant to conjugate Tn-MUC1 glycopeptide antigens using click chemistry to give vaccine candidates that induced potent tumour-specific IgG antibody responses ${ }^{114}$. In another example, an immunostimulatory $6^{\prime}$-deoxy- $6^{\prime}$-thio analogue was synthesized and attached to the MHC-I OVA $257-264$ epitope via disulfide or triazole linkages, yielding vaccine constructs that elicited potent, peptide-specific cytotoxic $\mathrm{T}$ lymphocyte responses in vivo, at levels higher than the unconjugated components ${ }^{115}$.

Notably, Anderson et al. developed a strategy based on an observed reversible rearrangement within the ceramide portion to link, via oxime and/or triazole linkages, peptide antigens to an $\alpha$-GalCer pro-adjuvant, in which the acyl chain is deliberately rearranged. Upon $\mathrm{O} \rightarrow \mathrm{N}$ acyl chain isomerization, the corresponding peptideglycolipid conjugates enhanced $\mathrm{T}$ cell immunity and efficacies in allergy ${ }^{116}$, cancer $^{117}$ and influenza ${ }^{118}$ models.

\section{Mechanisms of action}

The adjuvant activity of $\alpha$-GalCer depends on iNKT cell activation and requires the interaction between the upregulated CD40 co-stimulatory molecule on dendritic cells and CD40L on iNKT cells. Together with the induced increase in pro-inflammatory cytokines, this results in an adjuvant effect that enhances dendritic cell activity and, subsequently, T cell activation (FIG. 2d), including CD8 $\mathrm{T}$ cell cross-priming ${ }^{119,120}$. Moreover, iNKT cell activation enhances B cell activity and antibody production, dependent on the interaction between CD1- $\alpha$-GalCer complexes on B cells and dendritic cells with $\mathrm{T}$ cell receptors on iNKT cells ${ }^{121}$.

Extensive SAR studies on $\alpha$-GalCer glycolipids have improved understanding of the molecular mechanisms responsible for controlling iNKT cell activation, enabling rational design of improved synthetic $\alpha$-GalCer variants for more precise and predictable immune targeting. These mechanisms include the impact of $\alpha$-GalCer structure on the affinity of the interaction between the $\mathrm{T}$ cell receptor and the CD1d-glycolipid complex, and the effects on the kinetics and cellular pathways involved in glycolipid presentation by CD1d. While an early simple model attributed high $\mathrm{T}$ cell receptor affinities to $\mathrm{T}_{\mathrm{H}} 1$ skewing, the affinity of the $\mathrm{T}$ cell receptor/CD1dglycolipid interaction does not fully correlate with the induced cytokine bias. Additionally, other factors, such as the half-life of the ternary complex and the uptake and presentation by antigen-presenting cells, are important for iNKT cell activation and the induced cytokine profile $^{122}$.

In general, $\mathrm{T}_{\mathrm{H}} 1$-biased responses seem to be favoured by modifications that stabilize $\alpha$-GalCer presentation and $\mathrm{T}$ cell receptor/CD1d- $\alpha$-GalCer complexes, namely, $\mathrm{O}$-to- $\mathrm{C}$ replacement in the carbasugar and $\mathrm{a}-\mathrm{C}-\mathrm{GalCer}$ variants, and by variations that increase hydrophobicity, such as incorporation of aromatic groups at the 6" position and at the lipid chains terminus. On the other hand, $\mathrm{T}_{\mathrm{H}} 2$ immunity is promoted by modifications that decrease the half-life of the ternary complex, slightly disturb ligand presentation or improve glycolipid aqueous solubility, such as invariants with shortened, unsaturated or hydroxylated lipid moieties ${ }^{60}$. This solubility effect is related to differences in requirements for cellular uptake and intracellular loading of the glycolipids onto CD1d. While $\mathrm{T}_{\mathrm{H}} 1$-biasing $\alpha$-GalCer analogues require internalization by antigen-presenting cells and endosomal-dependent presentation by CD1d molecules in plasma membrane lipid rafts, less hydrophobic $\mathrm{T}_{\mathrm{H}}$ 2-skewing $\alpha$-GalCer analogues can be loaded directly into cell surface CD1d outside of lipid rafts ${ }^{123}$. Thus, lipid raft localization is likely one major mechanism responsible for cytokine biasing and emerges as a powerful tool in the functional screening of new variants ${ }^{124}$ for the development of tailored synthetic a-GalCer-based adjuvants.

\section{Lipopolysaccharide-based adjuvants}

Lipopolysaccharides, commonly known as endotoxins, represent a wide and highly heterogeneous class of bacterial outer membrane glycolipids from Gram-negative bacteria (e.g. Escherichia coli, Neisseria meningitidis and Salmonella minnesota $)^{125}$. They are essential for bacterial survival and have endotoxic properties that can be exploited in the context of vaccine adjuvants ${ }^{126}$. Lipopolysaccharides are sensed by the immune system 
principally via membrane-bound TLR4, which recognizes lipopolysaccharides extracellularly or within endosomes, inducing a signalling cascade that results in inflammation and the release of pro-inflammatory cytokines. More recently, TLR4-independent lipopolysaccharide recognition systems have also been identified: transient receptor potential channel-dependent sensing of extracellular lipopolysaccharide in neuronal cells and caspase $4 / 11$ as a cytoplasmic sensor of intracellular lipopolysaccharide within the innate immune cells (e.g. macrophages) that leads to secretion of pro-inflammatory cytokines IL- $1 \beta$ and IL-18 and inflammatory cell death ${ }^{127}$. Thus, lipopolysaccharides trigger innate immunity via caspase-mediated non-canonical inflammasome activation, as well as TLR4 binding ${ }^{128}$, leading to production of pro-inflammatory cytokines such as tumour necrosis factor (TNF), IL-1 and IL-6.

Lipopolysaccharides are composed of an external repeating $\mathrm{O}$-antigen polysaccharide chain, a core oligosaccharide and the highly conserved TLR4activating lipid $\mathrm{A}$, which comprises a phosphorylated $\beta(1 \rightarrow 6)$-linked glucosamine disaccharide esterified at $\mathrm{C} 2, \mathrm{C} 3, \mathrm{C} 2{ }^{\prime}$ and $\mathrm{C} 3^{\prime}$, with fatty acid chains varying in length and number, depending on the species ${ }^{129}$ (FIG. 3a,b). Lipid A has potent adjuvant activity, but the massive immune response it induces, characterized by sepsis and septic shock, has limited its clinical use. This has led to the development of potent and less toxic lipid A-based immunomodulators such as the clinically approved MPLA adjuvant ${ }^{130}$ (FIG. 3c). The bioactivity of lipid A and MPLA is strongly influenced by its heterogeneous chemical composition, comprising a number of carbohydrate functionalities that could influence their properties, as well as TLR4 binding and signalling. To address this limit on their clinical use, synthetic chemistry has emerged as an attractive means to provide practical access to structurally defined derivatives with distinct, potentially improved, clinical and immunological properties.

\section{Structure-activity relationship studies and variants of lipid $A$}

Extensive studies using natural and, especially, synthetic lipid A variants with modifications on the sugar, phosphorylation and acyl chain pattern (number and length) have provided key SAR insights that distinguish between agonistic and antagonistic activities, as well as disconnecting lipid A adjuvant activity from its pro-inflammatory toxicity ${ }^{131-134}$.

Boons and colleagues synthesized several monophosphorylated and diphosphorylated lipid A derivatives by selective acylation of an appropriately functionalized disaccharide intermediate at its $\mathrm{C} 2, \mathrm{C} 3, \mathrm{C} 2{ }^{\prime}$ and C3' positions, revealing important acyl chain features in terms of number (six versus seven), pattern (symmetrical $3+3$ over asymmetrical $4+2$ arrangement) and length (shorter versus longer) that induce higher TLR4 activation and pro-inflammatory cytokines ${ }^{135}$. The synthetic monophosphorylated derivatives exhibited less agonistic activity, confirming previous SAR studies $^{136,137}$, and in agreement with the reduced toxicity shown by MPLA $^{138}$ (FIG. 3c,d). Moreover, synthetic lipid A analogues containing the core oligosaccharide Kdo (3-deoxy-D-manno-octulosonic acid) units were more active than those lacking this moiety, highlighting its importance for agonistic activity ${ }^{139}$. Analogues with phosphate-to-carboxylic-acid substitution retained agonistic activity ${ }^{140-142}$, while monosaccharide deletion decreased lipid A potency but also toxicity, yielding simplified variants with encouraging therapeutic profiles $^{143,144}$. Collectively, the 3:1 ratio between acyl chains and phosphate groups seems to be important for agonistic activity ${ }^{145}$. Notably, replacement of the reducing glucosamine unit with an $\mathrm{N}$-acylated aglycon provided aminoalkyl glucosaminide phosphate monosaccharide analogues with adjuvant activity such as RC-529 (Ribi.529) ${ }^{146,147}$.

Semi-synthetic E. coli-derived MPLA analogues have also been developed by site-selective chemical modification of the lipid pattern (in terms of number, length and position of the acyl chains), the $4^{\prime}$-phosphate and the $6^{\prime}$-hydroxyl group, which was oxidized to the carboxylic acid to then insert an olefin handle for further functionalization. One of such variants bearing a pentenyl moiety at the $\mathrm{C6}^{\prime}$ position induced a similar cytokine profile to MPLA, highlighting its promising adjuvant activity, and was conjugated to a Tn antigen derivative via thiol-ene coupling to generate a self-adjuvanting vaccine candidate $^{148}$ (see below). Most recently, rigid $\alpha-\operatorname{GlcN}\left(1 \leftrightarrow 1^{\prime}\right) \alpha$-Man skewed lipid A mimetics were rationally designed and synthesized, eliciting controllable TLR4 activation and caspase 4/11 oligomerization without inducing caspase 11 protease activity and the associated toxicity ${ }^{149}$.

Monophosphoryl lipid A. MPLA (3-O-desacyl-4'monophosphoryl lipid A, MPL from GSK), a detoxified S. minnesota R595 lipid A analogue obtained through hydrolysis of the 1-O-phosphono and $(R)$-3hydroxytetradecanoyl groups ${ }^{150}$ (FIG. 3c), is the most clinically relevant lipid A derivative ${ }^{5}$. MPLA has been shown to increase antibody and cellular responses without the toxicity associated with lipid $\mathrm{A}$, and has been approved as part of the alum-containing AS04 Adjuvant System in vaccines against $H P V^{151}$ and hepatitis $B^{152}$. Successful MPLA combinations with other adjuvants such as QS-21 have also been developed (i.e. AS15, AS02 and, especially, the clinically approved AS01) that induce synergistic immunopotentiating activities and more effective immune responses against a number of infectious diseases and cancers ${ }^{153-155}$.

Several studies have exploited MPLA as both a carrier and an adjuvant by covalently linking different haptens/ antigens to its $6^{\prime}$ position to create a variety of MPLA derivatives. In an early example, a semi-synthetic trinitrophenol-MPLA conjugate, functionalized through an amino chemical handle at the $\mathrm{C}^{\prime}-\mathrm{OH}\left(\mathrm{REF}^{156}\right)$, elicited high titres of anti-trinitrophenol IgG antibodies in mice, highlighting MPLA as a T cell-independent carrier for induction of humoral immunity ${ }^{157}$. An alternative semi-synthetic approach involved derivatization of the $\mathrm{C}^{\prime}-\mathrm{OH}$ of $E$. coli-derived MPLA to install reactive moieties (azides, alkynes, olefins or thiols) for further conjugation (of the alkene-bearing MPLA derivative) 


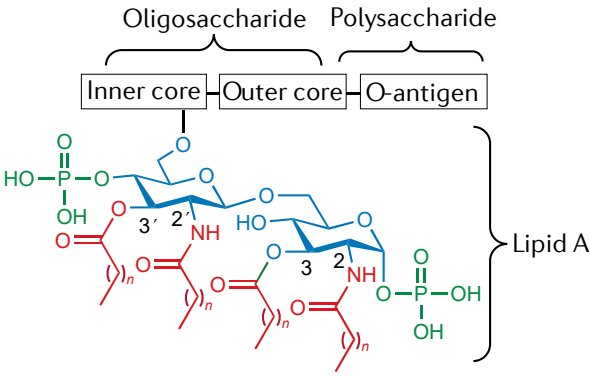

C

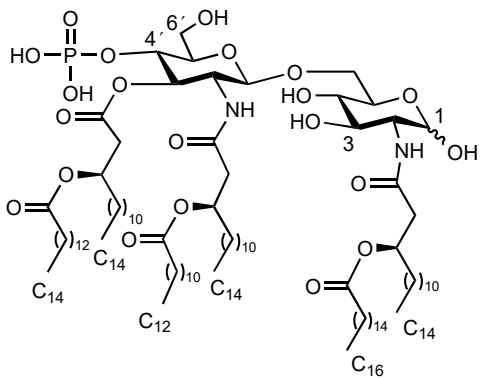

3-O-desacylmonophosphoryl S. minnesota R595 lipid A

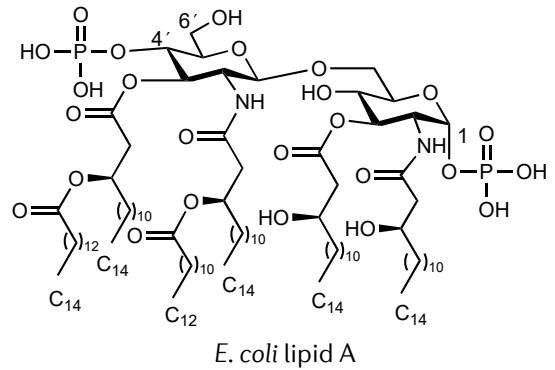

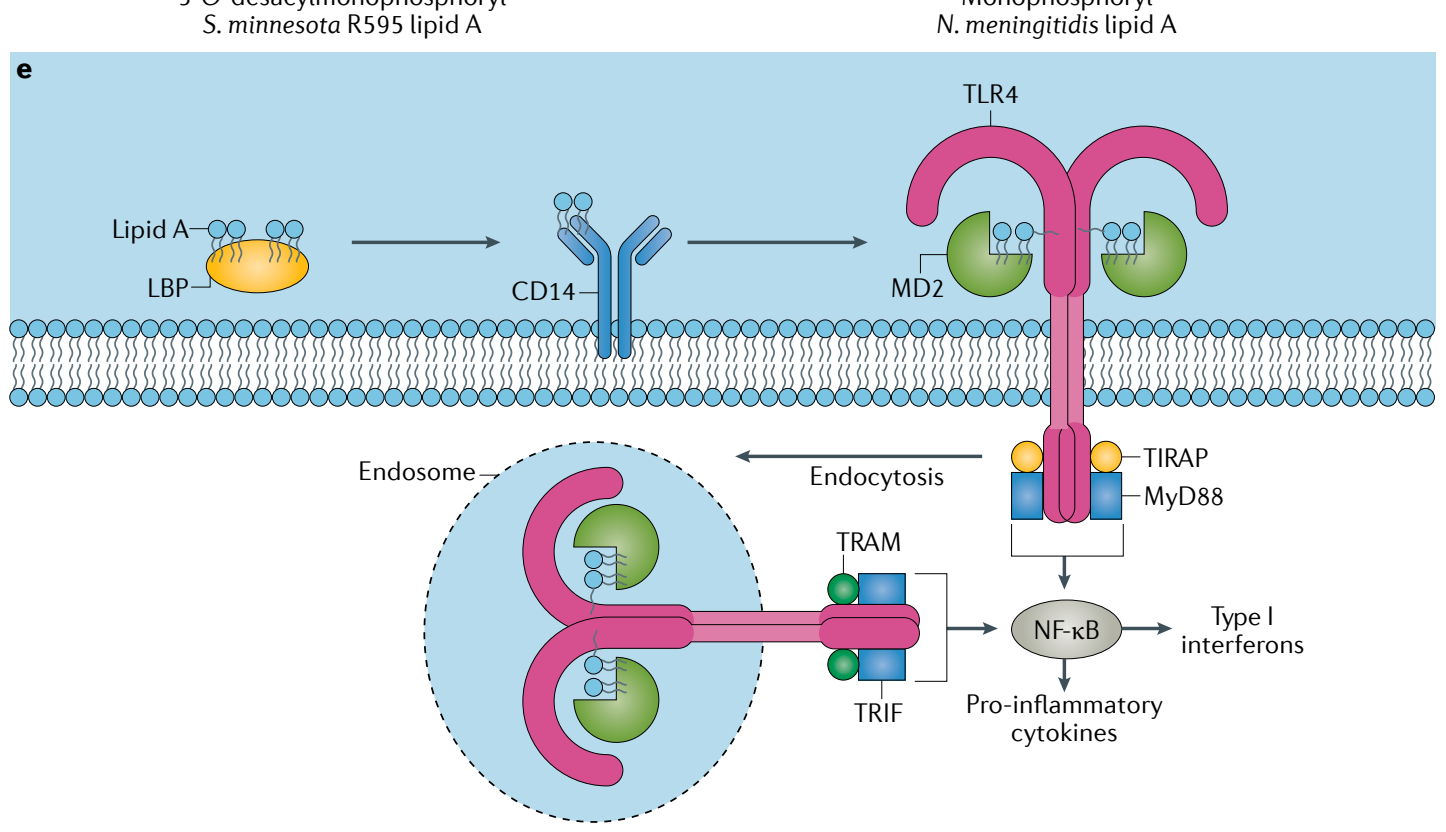

Fig. 3 | Structures of lipid A and monophosphoryl lipid A and its mechanism of action. a | General structure of lipopolysaccharide (LPS) with its three main domains, lipid A, core oligosaccharide and O-antigen polysaccharide. b | Structure of natural lipid A from Escherichia coli ${ }^{134} . \mathbf{c}, \mathbf{d}$ | Structures of chemically modified monophosphoryl lipid A from Salmonella minnesota R595 (clinically approved, panel c) ${ }^{147}$ and from Neisseria meningitidis (panel d) ${ }^{134}$. e | Schematic representation of LPS/Toll-like receptor 4 (TLR4) signalling pathway and lipid A mechanism of action ${ }^{166}$. LPS-binding protein (LBP)-associated LPS (or lipid A) is first transferred to CD14 and then delivered to myeloid differentiation factor 2 (MD2), enabling formation of the LPS-MD2-TLR4 ternary complex, which drives dimerization of TLR4 receptors. LPS/TLR4 signalling involves intracellular recruitment of Toll/interlukin-1 (IL-1) receptor domain-containing adapter protein (TIRAP), TRIF-related adapter molecule (TRAM), myeloid differentiation factor 88 (MyD88) and Toll/IL-1 receptor domain-containing adapter inducing interferon- $\beta$ (TRIF) co-receptors. While the MyD88-dependent pathway promotes pro-inflammatory cytokine expression, the MyD88-independent pathway mediates the induction of type I interferons. Part $\mathbf{e}$ adapted with permission from REF. ${ }^{132}$, Wiley, and with permission from REF. ${ }^{166}$, Elsevier.

with thiol-containing $\mathrm{Tn}$ and $\mathrm{TF}(\mathrm{Gal}(\beta 1 \rightarrow 3) \alpha-G a l N A c)$ antigens, providing MPLA-tumour-associated carbohydrate antigen (TACA) conjugates that induced increased production of pro-inflammatory cytokines (IL-6, TNF and IFN $\gamma$ ) in vitro with low toxicity ${ }^{158}$. Over the past decade, Guo and colleagues have chemically synthesized and evaluated several fully synthetic, self-adjuvanting vaccine candidates ${ }^{134}$ based on the $N$. meningitidis ${ }^{159}$ (FIG. $3 d$ ) and E. coli ${ }^{160}$ MPLA structures conjugated to bacterial antigens ${ }^{161}$ and TACAs ${ }^{162-164}$. In mouse immunizations, liposomal formulations of these constructs generally elicited high levels of antigen-specific 
IgG antibodies that mediated toxicity to the bacterial cell ${ }^{161}$ and complement-dependent cytotoxicity to the antigen-expressing MCF-7 cancer cell.

\section{Mechanisms of action}

The mechanism of action of lipopolysaccharide starts with binding of lipid A to lipopolysaccharide-binding protein, which transfers lipopolysaccharide to the CD14 receptor and then to the co-receptor protein myeloid differentiation factor 2 (MD2), which is associated to TLR4 forming a heterodimer, and directly binds lipid $\mathrm{A}^{165,166}$ (FIG. 3e). The acyl chains of lipid A interact specifically with the MD2 hydrophobic region, while the disaccharide phosphate groups make electrostatic and hydrogen-bond interactions with charged residues in MD2 and TLR4, promoting dimerization of the lipopolysaccharide/MD2/TLR4 complex ${ }^{167,168}$. This, in turn, results in dimerization of the intracellular Toll/ interlukin-1 receptor (TIR) domains of TLR4, initiating the lipopolysaccharide/TLR4 signalling pathway through two distinct intracellular cascades by recruitment of four adapter proteins: MyD88, TIR domain-containing adapter protein (TIRAP; also known as Mal), TRIF-related adapter molecule (TRAM) and Toll/IL-1 receptor domain-containing adapter inducing IFN $\beta$ (TRIF) ${ }^{169}$. The MyD88-dependent pathway involves recruitment of TIRAP and MyD88 to the TIR domain, resulting in early activation of NF- $\kappa \mathrm{B}$, strong production of pro-inflammatory cytokines such as TNF and IL- $1 \beta$, and $\mathrm{T}_{\mathrm{H}} 1$ cell responses ${ }^{170}$. The TRIF/TAMdependent pathway involves CD14-mediated TLR4/MD2 internalization into endosomes ${ }^{171}$ and induces late-stage $\mathrm{NF}-\kappa \mathrm{B}$ activation with lower levels of pro-inflammatory cytokines. It also activates the transcription factor IRF3, which leads to IFN $\beta$ and IFN-inducible gene expression with production of type I interferons ${ }^{172,173}$ (FIG. 3e). More recently, the cysteine protease caspase $4 / 11$ has been discovered as a cytosolic lipopolysaccharide receptor that activates the non-canonical NLRP3 inflammasome pathway via intracellular lipopolysaccharide interaction independent of TLR4 (REFS ${ }^{174-176}$ ), adding further complexity to the receptor-mediated, lipopolysaccharide-induced cellular activation that triggers innate immunity ${ }^{128}$. This caspase 11-dependent lipopolysaccharide-sensing pathway and NLRP3 inflammasome activation is associated with adjuvant effects by maximally promoting inflammation via caspase 1 -mediated maturation of the pro-inflammatory IL- 1 family cytokines (IL- $1 \beta$ and $(\mathrm{L}-18)^{128}$, and by driving pyroptosis, a caspase 1-dependent inflammatory cell death ${ }^{177}$.

The attenuated pro-inflammatory cytokine production and lower toxicity of MPLA has been associated with the preferential induction of TRIF signalling over the MyD88 pathway ${ }^{178}$, which is caused by MPLA's weak ability to form CD14-mediated TLR4/MD2 heterotetramers at the plasma membrane owing to the lack of the 1-O-phosphate group ${ }^{179,180}$. Additional explanations of MPLA-attenuated toxicity are related to its inability to activate caspase 1 , which results in reduced production of pro-inflammatory cytokines such as IL-1 and IL-18 (REF. ${ }^{181}$ ), and, alternatively, to its ability to induce high levels of the anti-inflammatory cytokine IL-10 (REF. ${ }^{182}$ ).
MPLA is able to induce TNF independently of CD14 via MyD88 signalling and to induce TRIF-mediated responses that include upregulation of the co-stimulatory molecule CD86 and IFN $\beta$ induction, thus retaining significant lipid A immunostimulatory activity without its associated toxicity. These favourable features have fuelled its successful clinical advancement as an adjuvant for human vaccines ${ }^{153}$. MPLA is reported to recruit and activate antigen-presenting cells such as dendritic cells to produce cytokines and co-stimulatory molecules that induce IFN $\gamma$ production by antigen-specific $\mathrm{CD}^{+}$ T cells, promoting a $\mathrm{T}_{\mathrm{H}} 1$-skewed or mixed $\mathrm{T}_{\mathrm{H}} 1 / \mathrm{T}_{\mathrm{H}} 2$-type immune response, depending on the co-administered antigen and route of administration ${ }^{183-185}$. The impaired TLR4 activation by MPLA via TRIF-mediated signalling has been shown to influence $\mathrm{CD} 8^{+} \mathrm{T}$ cell responses, promoting lower memory $\mathrm{CD}^{+} \mathrm{T}$ cell-mediated protective immunity than lipopolysaccharide in immunized mice ${ }^{186}$. In non-human primates, MPLA induced systemic expansion of neutrophils and $\mathrm{CD} 14^{+} \mathrm{CD} 16^{-}$ monocytes with subsequent migration to the lymph nodes, correlating with local pro-inflammatory gene transcription $^{187}$.

\section{Zwitterionic polysaccharide adjuvants}

In general, carbohydrates have traditionally been considered T cell-independent antigens ${ }^{188}$, typically triggering the innate immune system and inducing weak antibody responses, without affinity maturation and isotype switching. To achieve $\mathrm{T}$ cell-dependent $\mathrm{B}$ cell responses, carbohydrate-based epitopes have classically been conjugated to immunocarrier proteins that serve both as a scaffold for multivalent epitope presentation and as a source of $\mathrm{CD}^{+}$peptide epitopes for $\mathrm{T}_{\mathrm{H}}$ cell activation $^{189,190}$. These activated $\mathrm{T}_{\mathrm{H}}$ cells provide $\mathrm{B}$ lymphocytes with co-stimulatory signals via CD40L/CD40 co-receptor interaction, which, together with the secreted cytokine milieu, ultimately leads to the generation of high-affinity, isotype-switched IgG antibodies and a memory effect.

Zwitterionic polysaccharides are immunomodulatory bacterial polysaccharides bearing high density of positively and negatively charged carbohydrate residues ${ }^{191}$. The most prominent zwitterionic polysaccharides include polysaccharide (PS) A1, PS A2 and PS B, which were isolated from a Bacteroides fragilis strain. These carbohydrate structures have branched repeating units of four, five and six monosaccharides, respectively, with each oligosaccharide unit bearing one amino and carboxylate group, plus an additional phosphonate residue in the case of PS B ${ }^{192,193}$ (FIG. 4a). The S. pneumoniae type 1 polysaccharide ( $\mathrm{Sp} 1)$ contains a linear trisaccharide motif comprising a cationic amine-containing monosaccharide, followed by two negatively charged (carboxylate-bearing) sugar residues ${ }^{194}$ (FIG. 4b). Capsular polysaccharides from Staphylococcus aureus type 5 (CP 5) and type 8 (CP 8 ) share a similar linear trisaccharide repeating unit with zwitterionic character but differ in acetylation sites and linkages between sugars $^{195}$ (FIC. 4C).

Unlike other carbohydrate antigens, zwitterionic polysaccharides are considered T cell-dependent antigens, as 


\section{MHC-II molecules}

Transmembrane proteins on the surface of professional antigen-presenting cells that present processed antigens to Thelper cells, enabling antigen recognition in a ternary complex with the $\mathrm{CD}_{4}{ }^{+} \mathrm{T}$ cell receptor. they can be recognized by and activate $\mathrm{T}_{\mathrm{H}}$ cells through the following mechanism. Upon processing, presentation of zwitterionic polysaccharide fragments to $\mathrm{CD}^{+} \mathrm{T}_{\mathrm{H}}$ cells by antigen-presenting cells occurs on the cell surface in complex with MHC-II molecules. Following interaction through $\mathrm{T}$ cell receptors, the resulting activated $\mathrm{T}_{\mathrm{H}}$ cells produce cytokines and bind to $\mathrm{B}$ cells, whose activation leads to IgM-to-IgG class switching and affinity maturation with production of high-affinity IgG antibodies and memory B cells ${ }^{196}$. However, in addition to their antigen function, zwitterionic polysaccharides have further immunostimulatory properties and their role as adjuvants is well known, especially when co-administered with poorly immunogenic antigens.

The unique structures and activity of these zwitterionic polysaccharides have encouraged researchers to chemically modify natural bacterial PS and to develop synthetic versions and new zwitterionic polysaccharide conjugates that have been investigated in immunological and mechanistic studies.
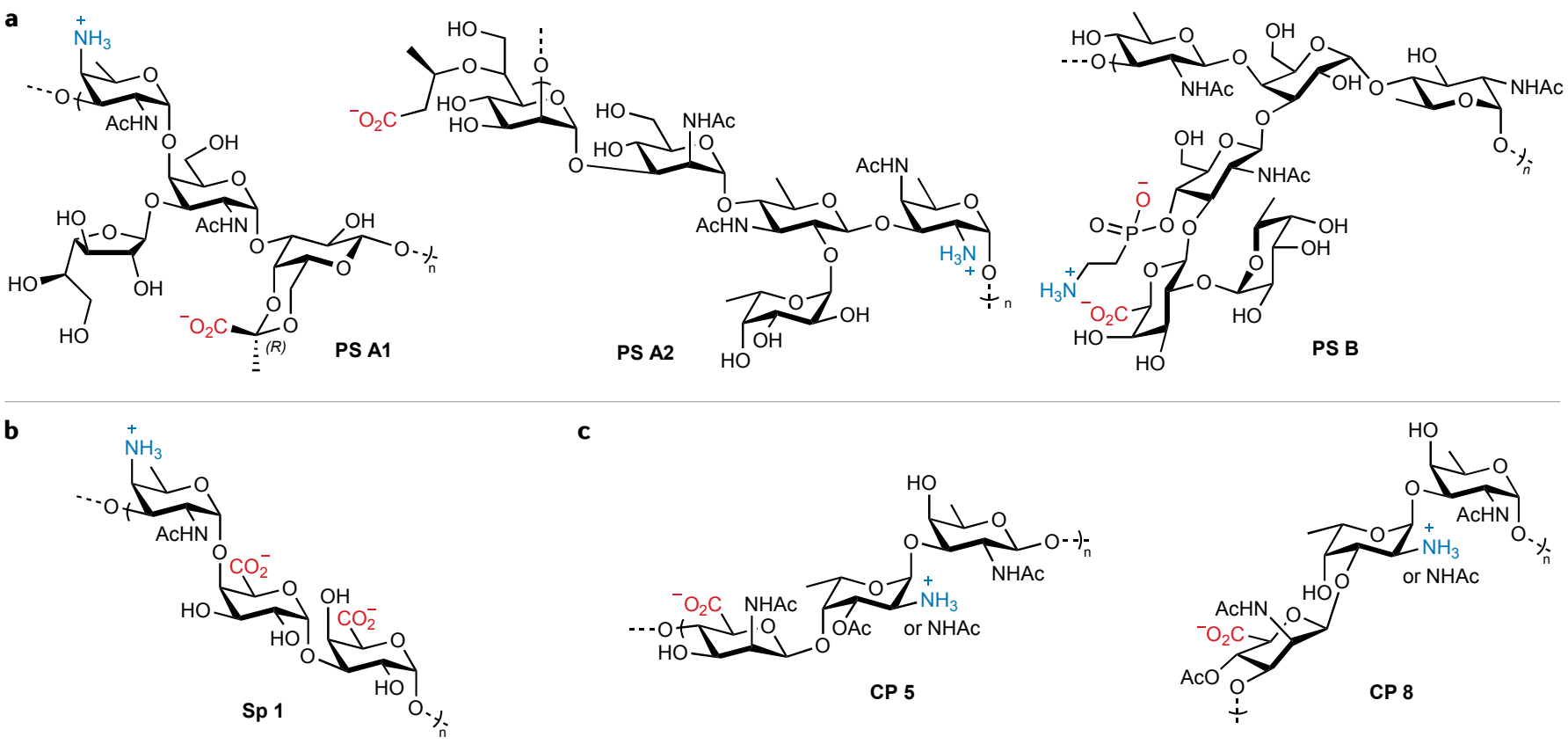

c

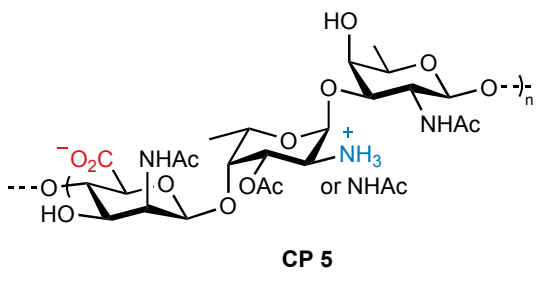

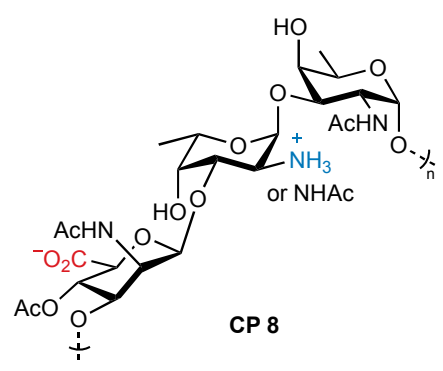

d

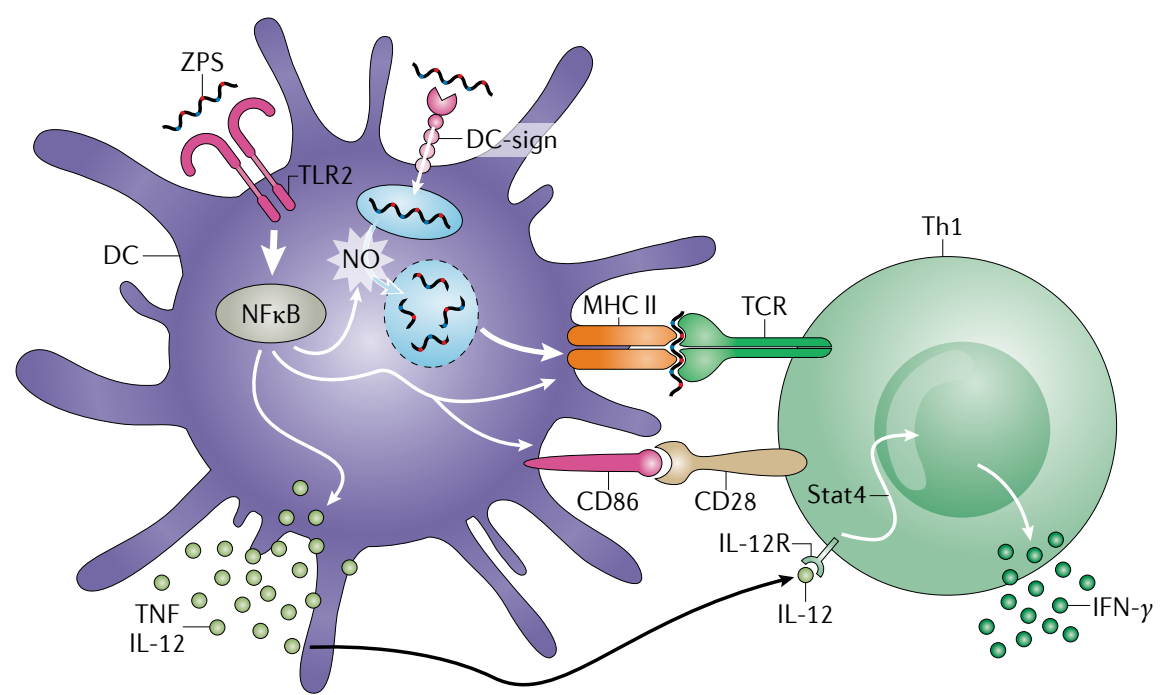

Fig. 4 | Structures of natural zwitterionic polysaccharides and their proposed mechanism of action. a | Structures of natural zwitterionic polysaccharides (ZPSs) PS A1, PS A2 and PS B from Bacteroides fragilis ${ }^{191}$. b,c $\mid$ Structures of natural ZPSs from Streptococcus pneumoniae (type 1, Sp 1, panel b) and Staphylococcus aureus (type 5, CP5, and type 8, CP8, panel c) ${ }^{202}$. d) Schematic representation of the proposed model for ZPS mechanism of action and crosstalk between innate and adaptive immune compartments ${ }^{215}$. Within the innate immunity context (left), Toll-like receptor 2 (TLR2)mediated recognition of zwitterionic polysaccharide induces the activation of the myeloid differentiation factor 88 (MyD88)-dependent pathway in antigen-presenting cells (e.g. dendritic cells), leading to NF- $\kappa B$-dependent pro-inflammatory cytokine expression (tumour necrosis factor (TNF), interleukin-12 (IL-12)), NO production, and MHC class II (MHC-II) and co-stimulatory molecule expression and upregulation. Adaptive immunity events (right) involving interaction between T cell receptor (TCR) and processed ZPSs presented on MHC-II, along with co-stimulation via CD86/ CD28 and IL-12/IL-12R interactions, ultimately trigger ZPS-activated $\mathrm{CD}^{+} \mathrm{T}$ cells to produce the Thelper $1\left(\mathrm{~T}_{\mathrm{H}} 1\right)$ cytokine interferon- $\gamma(\mathrm{IFN} \gamma)$. DC, dendritic cell. Part $\mathbf{d}$ adapted with permission from REF. ${ }^{215}$, Rockefeller University Press. 


\section{Structure-activity relationship studies and} semi-synthetic variants

Structural studies with naturally derived zwitterionic polysaccharide using NMR and molecular dynamics simulations ${ }^{192,197}$, as well as circular dichroism ${ }^{198}$, suggested key features responsible for zwitterionic polysaccharide immunological activity, namely, an $\alpha$-helical structure and the zwitterionic charge motif presented as alternating positive and negative charges on monosaccharide residues pointing at opposite sides of the helix. These zwitterionic repeating units are required for adjuvant properties, as chemical modifications of the charged amino and carboxylic groups abolished adjuvant activity ${ }^{191,199}$.

Wack and colleagues introduced, by rational chemical modification, positive charges into naturally anionic group B Streptococcus polysaccharides, generating chemically derived zwitterionic polysaccharide adjuvants that induced activation of antigen-presenting cells via TLR2 and of $\mathrm{T}$ cells in vitro ${ }^{200}$. Notably, co-administration of zwitterionic polysaccharide with tetanus toxoid in mice increased protein-specific IgG antibodies, highlighting its adjuvant activity in vivo. Compared with native polysaccharide conjugates, zwitterionic polysaccharide conjugation to the $\mathrm{CRM}_{197}$ carrier protein elicited higher anti-CRM $_{197}$ titres, superior TLR2-dependent protective antibody responses against bacterial polysaccharides and enhanced protein-specific but not zwitterionic polysaccharide-specific T cell responses, correlating with its ability to activate TLR2-expressing dendritic cells. However, zwitterionic polysaccharide alone did not induce anti-polysaccharide IgG antibodies, suggesting the need for the protein carrier and $\mathrm{T}$ cell help for zwitterionic polysaccharide immunogenicity ${ }^{201}$.

Zwitterionic polysaccharides have been the subject of several synthetic efforts by the chemistry community, including the chemical synthesis of the zwitterionic oligosaccharide repeating units of Sp1, PS A1, CP5, CP8 $\left(\right.$ REF. $^{202}$ ) and of the Morganella morganii zwitterionic polysaccharide ${ }^{203}$. The Andreana group synthesized the tetrasaccharide repeating unit of PS A1 using a linear glycosylation strategy ${ }^{204}$ and has also exploited the immunomodulatory and carrier properties of PS A1 and PS B to construct entirely carbohydrate-based conjugate vaccines incorporating the Tn, TF and STn TACAs ${ }^{205}$. The synthetic approach towards these conjugates involved site-specific chemical modification of PS A1 by oxidative cleavage of the D-galactofuranose vicinal diol, followed by oxime ligation through the resulting aldehyde with TACAs bearing aminooxy groups at their anomeric position. In their first example, a semi-synthetic Tn-PS A1 construct elicited strong Tn-specific IgG3 antibody responses in mice, highlighting the dual role of PS A1 as both a carrier and an adjuvant ${ }^{206}$. Subsequently, they prepared an STn-PS Al conjugate that, upon mouse immunization with an MPLA-derived adjuvant, generated robust cellular immunity with significant IFN $\gamma$ production and good levels of IgM/IgG antibodies that bound to STn-expressing cancer cells and induced complement-dependent cytotoxicity ${ }^{207}$. The same synthetic approach was used to access an oxime-linked TF-PS B construct, which generated high titres of TF-specific IgM antibodies and lower levels of IgG1/IgG2b isotypes ${ }^{208}$, a response differing from the $\mathrm{T}_{\mathrm{H}} 1 / \mathrm{T}_{\mathrm{H}} 17$ immunity induced by the TACA-PS A1 conjugates $^{209}$.

Recently, Codée and colleagues synthesized Sp1 oligosaccharides encompassing from one to four repeating units (3-12 residues) following an effective stereoselective preglycosylation/postglycosylation-oxidation strategy to assemble the glycan backbone and introduce the carboxylic acid groups. By use of molecular dynamics and NMR, they showed that the observed helical 3D structure, and especially the full helical turn adopted by the nonasaccharides and dodecasaccharides, is required for optimal interaction with anti-Sp1 antibodies, as assessed by binding studies using enzyme-linked immunosorbent assay (ELISA) and saturation transfer difference (STD) NMR ${ }^{210}$. This study identified the synthetic Sp1 nonamer and dodecamer as structural epitope mimics of the natural polysaccharide, holding promise for vaccine development and mechanistic studies to elucidate the structural basis of the zwitterionic polysaccharide-MHC-II interaction and their molecular mode of action.

\section{Mechanisms of action}

Kasper and colleagues first identified and reported a mechanism whereby, upon pinocytosis or receptormediated endocytosis in antigen-presenting cells, the zwitterionic polysaccharide PS A is presented by MHC-II molecules analogously to conventional protein-based antigens ${ }^{196,211}$. Zwitterionic polysaccharides are processed in endosomes, where a nitric-oxide-mediated oxidative burst produces shorter zwitterionic polysaccharide fragments $(12-15 \mathrm{kDa}$, corresponding to $\sim 15$ repeating units). These fragments are loaded onto MHC-II molecules, and the zwitterionic polysaccharide-MHC-II complex is presented on the antigen-presenting cell surface for interaction with $\mathrm{CD} 4^{+} \mathrm{T}$ cell receptors, which results in $\mathrm{T}$ cell proliferation and $\mathrm{T}_{\mathrm{H}}$ 1-type cytokine production (FIG. 4d). PS A uptake by dendritic cells has been shown to involve the dendritic cell-specific intercellular adhesion molecule-3-grabbing non-integrin (DC-SIGN) receptor ${ }^{212}$ and to induce cell maturation with increased expression of co-stimulatory CD80 and CD86 molecules. This, in turn, leads to T cell activation and IFN $\gamma$ production that requires dendritic cell secretion of IL-12 and activation of the STAT4 transcription factor ${ }^{213}$.

Interestingly, removal of the zwitterionic charges from PS A has been reported to abolish both in vitro and in vivo MHC-II binding, albeit without impairing antigen-presenting cell-mediated uptake, vesicular trafficking or processing ${ }^{199,214}$. In addition to DC-SIGN, TLR2 has been identified as a PS A receptor that plays a critical role in initiating the innate immune response and priming the adaptive immune responses to the polysaccharide. Upon TLR2 binding, PS A generates a signalling cascade in antigen-presenting cells that leads to several important events, including activation of NF- $\kappa \mathrm{B}$, production of pro-inflammatory TNF and other molecules that modulate adaptive immunity ${ }^{215}$.

With these data, an integrated model for PS A-dependent activation of dendritic cells and $\mathrm{CD} 4^{+} \mathrm{T}$ cells 
was proposed, linking the innate and adaptive immune system (FIG. 4d). PS A triggers the innate immunity arm in a TLR2-dependent fashion, resulting in NF- $\kappa \mathrm{B}-$ dependent production of nitric oxide, which is critical for the processing of DC-SIGN-endocytosed zwitterionic polysaccharide, enabling presentation of short zwitterionic polysaccharide fragments on MHC-II molecules. Interaction between zwitterionic polysaccharide-MHC-II complexes and $\mathrm{CD}^{+} \mathrm{T}$ cell receptors in conjunction with co-stimulation leads to production of IFN $\gamma$ by $\mathrm{CD}^{+} \mathrm{T}_{\mathrm{H}}$ cells, a process enhanced by IL-12 secretion by dendritic cells owing to TLR2 stimulation. Along these lines, TLR2-mediated dendritic cell activation has been proposed to be the mechanism of in vivo adjuvant activity and immunogenicity of natural zwitterionic polysaccharide and zwitterionic-polysaccharide-conjugated vaccines, leading to improved $\mathrm{T}$ cell priming and potent immune responses $^{201}$.

\section{Other carbohydrate-based adjuvants Mycobacterial carbohydrate adjuvants}

Lipoarabinomannans. Lipoarabinomannan is the major mycobacteria cell wall glycolipid component, and comprises an acylated phosphatidyl-myo-inositol anchor glycosylated with a mannan backbone and an arabinan branch that differ between mycobacteria species ${ }^{216}$. Depending on their lipopolysaccharide structure, lipoarabinomannans have varying immunomodulatory activities $^{217}$. They can activate MyD88 and complement pathways with production of pro-inflammatory cytokines (TNF, IL-12) ${ }^{218}$ via interaction with TLR2 and CLRs ${ }^{219}$ (dectin-2 (REF. ${ }^{220}$ ), mannose receptor ${ }^{221}$, ${\mathrm{DC}-\mathrm{SIGN}^{222} \text { ) on antigen-presenting cells }}^{223}$, but can also induce anti-inflammatory cytokines (IL-10) ${ }^{224}$, as reported for mannosylated lipoarabinomannans (ManLAMs) ${ }^{225}$, which highlights carbohydrate signalling intricacy.

Muramyl dipeptide. Muramyl dipeptide ( $N$-acetylmuramylL-alanine-D-isoglutamine) is a glycosylated dipeptide identified from a bacterial cell wall peptidoglycan fraction with adjuvant activity and constitutes the minimal immunoactive component of Freund's complete adjuvant ${ }^{226}$. Upon uptake via clathrin-mediated internalization, muramyl dipeptide binds the intracellular receptor NOD2 $\left(\mathrm{REF}^{227}\right)$, leading to NF- $\kappa \mathrm{B}$ and MAPK activation and induction of pro-inflammatory responses that promote dendritic cell differentiation and enhance $\mathrm{CD}^{+} \mathrm{T}$ cell cross-presentation ${ }^{228}$. Early in vivo studies with carbohydrate analogues of muramyl dipeptide highlighted the strict structural requirement of the monosaccharide residue for adjuvant activity ${ }^{229}$. More recently, NOD2 has been shown to recognize naturally occurring muramyl dipeptide variants with modifications in the dipeptide $e^{228}$.

\section{Pattern recognition} receptors

Family of cell surface proteins, including Toll-like and C-type

lectin receptors, that bind conserved molecular structures in pathogens, playing key roles in innate immune defence.

6se-6, 6' -dimycolate (TDM or cord factor). comprises an $\alpha$-D-glucopyranosyl- $\alpha$-D-glucopyranoside (trehalose) esterified with two $\alpha$-alkyl, $\beta$-hydroxy fatty acid long chains (mycolic acids) ${ }^{230}$. Its potent adjuvant activity, with induction of pro-inflammatory cytokines and cellular immunity, requires trehalose binding to the Mincle receptor ${ }^{231-233}$, and is mediated by the macrophage C-type lectin (MCL) $)^{234,235}$. This triggers SYK-CARD9-dependent NF- $\kappa \mathrm{B}$ activation, antigenpresenting cell maturation and robust $\mathrm{T}_{\mathrm{H}} 1 / \mathrm{T}_{\mathrm{H}} 17$ responses in vivo ${ }^{236}$. However, its high reactogenicity makes it unsuitable for human vaccines, leading to the development of simplified, similarly potent and less toxic synthetic Mincle ligands bearing shorter acyl chains. These include trehalose-6,6' -dibehenate $^{237}$ that is part of the potent $\mathrm{T}$ cell priming CAF01 adjuvant formulation $^{238-240}$, a glucose derivative acylated at $6-\mathrm{OH}$ with 2-tetradecyloctadecanoic acid (GlcC14C18) $)^{241}$ and a synthetic diacyl trehalose variant ${ }^{242}$. These analogues exemplify how current advances in synthetic chemistry and chemical biology contribute to developing structurally defined, potent adjuvant molecules.

\section{Polysaccharide-based adjuvants}

a-Glucans. Dextran ( $\alpha$-1,6-glucan with $\alpha$-1,3-branches) is an immunostimulatory microbial polysaccharide of glucose that activates NF- $\kappa \mathrm{B}$ and induces proinflammatory responses ${ }^{14}$. Acetylated dextran microparticles have been used as antigen-adjuvant carriers, enabling their delivery and acid-mediated release, leading to increased MHC-I/MHC-II antigen presentation ${ }^{243}$ and enhanced humoral and cellular responses in vivo ${ }^{244}$. In mouse models, a lymph-node-targeting dextran-CpG adjuvant conjugate enhanced tumour-specific $\mathrm{T}_{\mathrm{H}} 1$ and cytotoxic $\mathrm{T}$ lymphocyte responses to protein vaccines, leading to protective antitumour immunity ${ }^{245,246}$, highlighting the applicability of dextran as an adjuvant and a carrier for cancer immunotherapy.

$\beta$-Glucans. $\beta$-Glucans are microorganism-derived linear or branched $\beta$-1,3-glucose polysaccharides that bind to C-type lectin dectin-1 and other pattern recognition receptors, such as CR3 on myeloid immune cells, promoting cytokine production and $\mathrm{B} / \mathrm{T}$ cell activation, leading to enhanced humoral and cellular responses ${ }^{247}$. Their adjuvant activity stimulates innate and adaptive immunity through different pathways, depending on their source, structure and formulation. Zymosan (a yeast cell wall mixture of $\beta$-1,3-glucans) also activates TLR2, inducing NF- $\kappa B$ activation and TNF secretion ${ }^{248}$, albeit was later reported to induce regulatory antigenpresenting cells and immune tolerance ${ }^{249}$. Particulate $\beta$-glucan activates dendritic cells via dectin-1, inducing cellular and antitumour immune responses, while soluble $\beta$-glucan primes neutrophils for complement and CR3mediated tumoricidal activity ${ }^{250}$. Notably, $\beta$-glucan was shown to reverse immune tolerance and restore cytokine production via dectin-1 ( REF. $\left.^{251}\right)$, highlighting its adjuvant potential for immunotherapy ${ }^{252}$. Recent studies have exploited $\beta$-glucan as a carrier and immune activator to develop synthetic conjugates that increased the immunogenicity of protein-based antigens $\left(\mathrm{CRM}_{197}, \mathrm{MUC1}\right)$, enhancing antigen-specific antibody responses ${ }^{253,254}$.
Fructans. Inulin is a plant-derived linear $\beta$-D- $(2 \rightarrow 1)$ polyfructofuranosyl- $\alpha$-D-glucose polysaccharide that exists as various isoforms, with the insoluble crystalline 
$\delta$-inulin having been developed as a potent adjuvant $(\text { Advax })^{255,256}$ in vaccine clinical trials against hepatitis B and influenza ${ }^{257,258}$. Mechanistically, Advax does not activate $\mathrm{NF}-\kappa \mathrm{B}$ and/or the inflammasome but the alternative complement pathway, and potentiates the intrinsic activity of the co-administered antigens via TNF signalling, showing low reactogenicity ${ }^{256,259,260}$. It enhances antigen uptake and presentation by recruiting and priming antigen-presenting cells, leading to a balanced increase of $\mathrm{T}_{\mathrm{H}} 1 / \mathrm{T}_{\mathrm{H}} 2$ antigen-specific cellular and humoral responses ${ }^{259,261}$.

Mannans. Mannan is a $\beta-1,4$-mannose polysaccharide produced by plants and fungi that enhances antigen presentation and TLR4-dependent dendritic cell maturation, potentiating immune responses ${ }^{262}$. It binds to mannan-binding lectin (MBL) and C-type lectin receptors, activating the complement pathway ${ }^{263}$. Mannan also activates the inflammasome, leading to caspase 1 and NF- $\kappa \mathrm{B}$ activation, with production of IL- $1 \beta$, IL- 6 and $\mathrm{TNF}^{264}$. Mannan structures either in native, oxidized or reduced form have been conjugated to protein-based antigens and carriers as antigen-presenting cell-targeting adjuvant systems, resulting in enhanced antigen uptake and presentation, and increased $\mathrm{T}_{\mathrm{H}} 1 / \mathrm{T}_{\mathrm{H}} 2$ responses ${ }^{265-269}$. Notably, clinical trials with oxidized mannan-MUC1 vaccine demonstrated its safety and immunogenicity, showing antibody and cellular clinical responses that protected patients with early-stage breast cancer from recurrence $\mathrm{e}^{270-272}$.

Chitosan. Chitosan is a partially chemically deacetylated form of chitin (poly $\beta$-1,4-N-acetyl-D-glucosamine) ${ }^{273}$ shown to potentiate humoral and cellular responses to co-administered antigens through a depot effect and by activating macrophages and NK cells via phagocytosis to produce inflammatory cytokines ${ }^{274-276}$. Chitosan can be internalized via charged-based interactions or receptor-mediated endocytosis, albeit no specific receptors have been identified ${ }^{277}$. It activates the NLRP3 inflammasome ${ }^{278}$ and the DNA-sensing cGAS-STING pathway that results in type I interferon-mediated dendritic cell maturation ${ }^{279}$, with both mechanisms being dependent on phagocytosis and lysosomal destabilization, and necessary for chitosan-promoted $\mathrm{T}_{\mathrm{H}} 1$ cellular responses $^{277,280}$. The cGAS-STING and inflammasome pathways are mutually exclusive, depending on the lysosomal disruption induced by distinct chitosan preparations, with a minimal 3,000-Da fully deacetylated chitosan moiety being required for type I interferon responses $^{280}$. Several chitosan formulations have been studied as carriers and adjuvants in preclinical settings, increasing vaccine delivery and immunogenicity, and potentiating immune responses ${ }^{275,281}$.

\section{Conclusions}

The development of novel, improved adjuvants is a pressing challenge intimately linked to understanding their mechanisms of action. Despite their history and key role, adjuvants have long been used without a real insight into how exactly they potentiate the immune response, and only a few adjuvants have demonstrated sufficient potency and low toxicity to be licensed for human vaccines. This lack of knowledge has hampered the rational design of more potent and safer adjuvants, and demands further mechanistic investigations to fuel vaccine development. Carbohydrates play pivotal roles in nature, being involved in many important events in the context of the immune system. In addition, they are generally biocompatible, safe and well tolerated, which are intrinsic, favourable properties that make carbohydrate structures attractive targets for the development of vaccine adjuvants and immunomodulators. Chemical synthesis is emerging as a powerful approach on this front, providing practical access to homogeneous carbohydrate compounds for adjuvant development, as well as enabling further SAR studies towards improved synthetic analogues. In this Review, we have covered recent advances in natural and synthetic carbohydrate-based adjuvants, including current understanding of their immunopotentiation mechanisms, along with selected applications in vaccines against infectious diseases and cancer. While there are important gaps in our knowledge on the exact mechanisms of action of many adjuvants, particularly saponin-based adjuvants for which no target receptor is currently known, advances in synthetic carbohydrate chemistry and newly developed chemical tools will aid in gaining new insights into the molecular mechanisms underlying saponin immunopotentiation. It is expected that this progress will make it possible for both chemists and immunologists to rationally design and develop novel, carbohydrate-based adjuvants with enhanced efficacy and reduced toxicity for further clinical advancement in human vaccines.

Published online 25 January 2021
1. Jones, L. H. Recent advances in the molecular design of synthetic vaccines. Nat. Chem. 7, 952-960 (2015)

2. Reed, S. G., Orr, M. T. \& Fox, C. B. Key roles of adjuvants in modern vaccines. Nat. Med. 19, 1597-1608 (2013). This review provides a comprehensive account on the benefits of adjuvants in vaccines, with formulation and mechanistic insights on adjuvants that are licensed or in clinical phase.

3. Flach, T. L. et al. Alum interaction with dendritic cell membrane lipids is essential for its adjuvanticity. Nat. Med. 17, 479-487 (2011).

4. HogenEsch, H., O'Hagan, D. T. \& Fox, C. B. Optimizing the utilization of aluminum adjuvants in vaccines: you might just get what you want. NPJ Vaccines 3, 51 (2018).

5. Del Giudice, G., Rappuoli, R. \& Didierlaurent, A. M. Correlates of adjuvanticity: a review on adjuvants in licensed vaccines. Semin. Immunol. 39, 14-21 (2018).
6. Fox, C. B. \& Haensler, J. An update on safety and immunogenicity of vaccines containing emulsion-based adjuvants. Expert Rev. Vaccines 12, 747-758 (2013).

7. Sobolev, O. et al. Adjuvanted influenza-H1N1 vaccination reveals lymphoid signatures of agedependent early responses and of clinical adverse events. Nat. Immunol. 17, 204-213 (2016).

8. Givord, C. et al. Activation of the endoplasmic reticulum stress sensor IRE 1 a by the vaccine adjuvant ASO3 contributes to its immunostimulatory properties. NPJ Vaccines 3, 20 (2018)

9. Didierlaurent, A. M. et al. Adjuvant system AS01: helping to overcome the challenges of modern vaccines. Expert Rev. Vaccines 16, 55-63 (2017).

10. Coccia, M. et al. Cellular and molecular synergy in AS01-adjuvanted vaccines results in an early IFN $\gamma$ response promoting vaccine immunogenicity. NPJ Vaccines 2, 25 (2017).
11. Bergmann-Leitner, E. \& Leitner, W. Adjuvants in the driver's seat: how magnitude, type, fine specificity and longevity of immune responses are driven by distinct classes of immune potentiators. Vaccines 2, 252-296 (2014).

This review describes the mode of action of several classes of adjuvants and stresses their key role in providing immune signals that coordinate the fate of the immune response.

12. van Kooyk, Y. \& Rabinovich, G. A. Protein-glycan interactions in the control of innate and adaptive immune responses. Nat. Immunol. 9, 593-601 (2008).

This review in the field of glycoimmunology provides an insightful overview on the multiple roles of glycans in the modulation of the immune system and their implications in important immunological processes. 
13. Fernández-Tejada, A., Cañada, F. J. \& JiménezBarbero, J. Glycans in medicinal chemistry: an underexploited resource. ChemMedChem 10, 1291-1295 (2015)

14. Petrovsky, N. \& Cooper, P. D. Carbohydrate-based immune adjuvants. Expert Rev. Vaccines 10, 523-537 (2011).

This review focuses on polysaccharide-based adjuvants as a promising class of immunostimulatory compounds with improved safety and tolerability properties, and provides a brief outline of regulatory and mechanistic aspects of carbohydrate adjuvants.

15. Fleck, J. et al. Saponins from Quillaja saponaria and Quillaja brasiliensis: particular chemical characteristics and biological activities. Molecules 24, 171 (2019).

16. Sun, H.-X., Xie, Y. \& Ye, Y.-P. Advances in saponinbased adjuvants. Vaccine 27, 1787-1796 (2009).

17. Kensil, C. R., Patel, U., Lennick, M. \& Marciani, D. Separation and characterization of saponins with adjuvant activity from Quillaja saponaria Molina cortex. J. Immunol. 146, 431-437 (1991).

18. Ragupathi, G., Gardner, J. R., Livingston, P. O. $\&$ Gin, D. Y. Natural and synthetic saponin adjuvant QS-21 for vaccines against cancer. Expert Rev. Vaccines 10, 463-470 (2011).

This review highlights the potency and promise of OS-21 as a vaccine adjuvant and signals the power of chemistry to enhance its potential and enable the development of designed synthetic saponin adjuvants.

19. Soltysik, S., Bedore, D. A. \& Kensil, C. R. Adjuvant activity of QS-21 isomers. Ann. N. Y. Acad. Sci. 690 392-395 (1993)

20. Hu, J. et al. Carbohydrate-based vaccine adjuvants discovery and development. Expert Opin. Drug Discov. 10, 1133-1144 (2015)

21. Kensil, C. R. Saponins as vaccine adjuvants. Crit. Rev. Ther. Drug Carrier Syst. 13, 1-55 (1996).

22. Laurens, M. B. RTS,S/AS01 vaccine (Mosquirix"): an overview. Hum. Vaccin. Immunother. 16, 480-489 (2019).

23. Bharucha, T., Ming, D. \& Breuer, J. A critical appraisal of 'Shingrix', a novel herpes zoster subunit vaccine (HZ/Su or GSK1437173A) for varicella zoster virus. Hum. Vaccin. Immunother. 13, 1789-1797 (2017)

24. Marciani, D. J. et al. Development of semisynthetic triterpenoid saponin derivatives with immune stimulating activity. Vaccine 18, 3141-3151 (2000).

25. Marciani, D. J., Pathak, A. K., Reynolds, R. C., Seitz, L. $\&$ May, R. D. Altered immunomodulating and toxicological properties of degraded Quillaja saponaria Molina saponins. Int. Immunopharmacol. 1, 813-818 (2001).

26. Marciani, D. J., Reynolds, R. C., Pathak, A. K Finley-Woodman, K. \& May, R. D. Fractionation structural studies, and immunological characterization of the semi-synthetic Quillaja saponins derivative GPI-0100. Vaccine 21, 3961-3971 (2003).

27. Wang, P., Dai, Q., Thogaripally, P., Zhang, P. \& Michalek, S. M. Synthesis of QS-21-based immunoadjuvants. J. Org. Chem. 78, 11525-11534 (2013)

28. Wang, P., Škalamera, Đ., Sui, X., Zhang, P. $\&$ Michalek, S. M. Synthesis and evaluation of a QS-17/18-based vaccine adjuvant. J. Med. Chem. 62 , 1669-1676 (2019).

29. Wang, P., Škalamera, Đ., Sui, X., Zhang, P. \& Michalek, S. M. Synthesis and evaluation of QS-7based vaccine adjuvants. ACS Infect. Dis. 5, 974-981 (2019).

30. Wang, P., Kim, Y. J., Navarro-Villalobos, M., Rohde, B. D \& Gin, D. Y. Synthesis of the potent immunostimulatory adjuvant QS-21A. J. Am. Chem. Soc. 127, 3256-3257 (2005).

This paper reports the first total synthesis of QS-21 specifically of QS-21 $1_{\text {Api }}$, which was accomplished in a highly modular and convergent fashion using nove glycosylation reactions.

31. Kim, Y. J. et al. Synthetic studies of complex immunostimulants from Quillaja saponaria: synthesis of the potent clinical immunoadjuvant QS-21A J. Am. Chem Soc 128, 11906-11915 (2006).

32. Deng, K. et al. Synthesis of QS-21-xylose: establishment of the immunopotentiating activity of synthetic QS-21 adjuvant with a melanoma vaccine. Angew. Chem. Int. Ed. Engl. 47, 6395-6398 (2008).

33. Deng, K., Adams, M. M. \& Gin, D. Y. Synthesis and structure verification of the vaccine adjuvant QS-7-Api. Synthetic access to homogeneous Quillaja saponaria immunostimulants. J. Am. Chem. Soc. 130 5860-5861 (2008).
34. Fernández-Tejada, A., Walkowicz, W. E., Tan, D. S. $\&$ Gin, D. Y. Semisynthesis of analogues of the saponin immunoadjuvant QS-21. Methods Mol. Biol. 1494, 45-71 (2017)

35. Adams, M. M. et al. Design and synthesis of potent Quillaja saponin vaccine adjuvants. J. Am. Chem. Soc 132, 1939-1945 (2010).

36. Fernández-Tejada, A Tan, D. S. \& Gin, D. Y. Development of improved vaccine adjuvants based on the saponin natural product QS-21 through chemical synthesis. Acc. Chem. Res. 49, 1741-1756 (2016). This review summarizes the extensive multidisciplinary studies on OS-21 and synthetic derivatives by the Gin group, which yielded critical insights into saponin structure-activity relationship and identified improved $Q S$ variants with potent adjuvant activity and low toxicity in vivo

37. Chea, E. K. et al. Synthesis and preclinical evaluation of QS-21 variants leading to simplified vaccine adjuvants and mechanistic probes. J. Am. Chem. Soc. 134, 13448-13457 (2012)

38. Fernández-Tejada, $\mathrm{A}$. et al. Development of a minimal saponin vaccine adjuvant based on QS-21. Nat. Chem 6, 635-643 (2014)

This paper describes the development of truncated synthetically accessible OS-21-derived variants that decoupled adjuvant from toxicity and presents early mechanistic studies using radioiodinated and fluorescent saponin probes

39. Fernández-Tejada, A. et al. Design, synthesis, and immunologic evaluation of vaccine adjuvant conjugates based on OS-21 and tucaresol. Bioorg. Med. Chem. 22, 5917-5923 (2014)

40. Walkowicz, W. E. et al. Quillaja saponin variants with central glycosidic linkage modifications exhibit distinct conformations and adjuvant activities. Chem. Sci. 7 2371-2380 (2016).

41. Ghirardello, M. et al. Exploiting structure-activity relationships of QS-21 in the design and synthesis of streamlined saponin vaccine adjuvants. Chem. Commun 56, 719-722 (2020).

42. Fernăndez-Tejada, A. Design, synthesis and evaluation of optimized saponin variants derived from the vaccine adjuvant QS-21. Pure Appl. Chem. 89, 1359-1378 (2017).

43. Škalamera, Ä., Kim, H., Zhang, P., Michalek, S. M $\&$ Wang, P. Impact of C28 oligosaccharide on adjuvant activity of QS-7 analogues. J. Org. Chem. https:/ doi.org/10.1021/acs.joc.0c00359 (2020). This work reports the synthesis and immunological evaluation of a series of progressively truncated linear oligosaccharide variants of QS-7, providing important SAR information on this Quillaja saponin adjuvant.

44. Pink, J. R. \& Kieny, M. P. 4th Meeting on novel adjuvants currently in/close to human clinical testing: World Health Organization - Organisation Mondiale de la Santê Fondation Mérieux, Annecy, France, 23-25, June 2003. Vaccine 22, 2097-2102 (2004).

45. Marciani, D. J. Vaccine adjuvants: role and mechanisms of action in vaccine immunogenicity. Drug Discov. Today 8, 934-943 (2003).

46. Detienne, S. et al Central role of CD169+ lymph node resident macrophages in the adjuvanticity of the QS-21 component of AS01. Sci. Rep. 6, 39475 (2016)

47. Welsby, I. et al. Lysosome-dependent activation of human dendritic cells by the vaccine adjuvant QS-21. Front. Immunol. 7, 663 (2017).

48. Lacaille-Dubois, M. A. Updated insights into the mechanism of action and clinical profile of the immunoadjuvant QS-21: a review. Phytomedicine 60, 152905 (2019).

49. Den Brok, M. H. et al. Saponin-based adjuvants induce cross-presentation in dendritic cells by intracellular lipid body formation. Nat. Commun. 7 , 13324 (2016)

50. Wilson, N. S. et al. ISCOMATRIX vaccines mediate CD8 T-cell cross-priming by a MyD88-dependent signaling pathway. Immunol. Cell Biol. 90, 540-552 (2012).

51. Wilson, N. S. et al. Inflammasome-dependent and -independent IL-18 production mediates immunity to the ISCOMATRIX adjuvant. J. Immunol. 192, 3259-3268 (2014)

52. Marty-Roix, R. et al. Identification of QS-21 as an inflammasome-activating molecular component of saponin adjuvants. J. Biol. Chem. 291, 1123-1136 (2016).

53. Marciani, D. J. Elucidating the mechanisms of action of saponin-derived adjuvants. Trends Pharmacol. SCi. 39, 573-585 (2018)

This review discusses currently available

information on saponin-based adjuvants and provides updated insights into the proposed mechanisms of action of QS-21.

54. Morita, M. et al. Structure-activity relationship of $\alpha$-galactosylceramides against B16-bearing mice. J. Med. Chem. 38, 2176-2187 (1995).

55. Girardi, E. \& Zajonc, D. M. Molecular basis of lipid antigen presentation by $\mathrm{CD} 1 \mathrm{~d}$ and recognition by natural killer T cells. Immunol. Rev. 250, 167-179 (2012).

56. Brennan, P. J., Brigl, M. \& Brenner, M. B. Invariant natural killer T cells: an innate activation scheme linked to diverse effector functions. Nat. Rev. Immunol. 13, 101-117 (2013)

This review discusses the underlying mechanisms of invariant natural killer $\mathrm{T}$ cell activation and the contribution of their various effector functions in the immune response.

57. Kawano, T. et al. CD1d-restricted and TCR-mediated activation of V(a) 14 NKT cells by glycosylceramides. Science 278, 1626-1629 (1997).

This paper reports the identification of $\alpha-G a l C e r$ as the first CD1 d-presented lipid antigen for invariant natural killer $T$ cells.

58. Godfrey, D. I., Uldrich, A. P., Mccluskey, J., Rossjohn, J. \& Moody, D. B. The burgeoning family of unconventional T cells. Nat. Immunol. 16, 1114-1123 (2015).

59. Savage, P. B., Teyton, L. \& Bendelac, A. Glycolipids for natural killer T cells. Chem. Soc. Rev. 35, 771-779 (2006).

60. Laurent, X. et al. Switching invariant natural killer T (iNKT) cell response from anticancerous to antiinflammatory effect: molecular bases. J. Med. Chem. 57, 5489-5508 (2014).

61. Koch, M. et al. The crystal structure of human CD1d with and without a-galactosylceramide. Nat. Immunol. 6, 819-826 (2005).

This paper reports the first crystal structure of human $\mathrm{CD} 1 \mathrm{~d}$ in complex with synthetic a-galactosylceramide.

62. Borg, N. A. et al. CD1d-lipid-antigen recognition by the semi-invariant NKT T-cell receptor. Nature $\mathbf{4 4 8}$, 44-49 (2007)

This study describes the structure of the trimolecular TCR- $\alpha$ GalCer-CD 1d complex and defines the unique mode of antigen recognition by iNKT cells, which is distinct from the recognition of peptide-MHC complexes.

63. Hung, J.-T., Huang, J.-R. \& Yu, A. L. Tailored design of NKT-stimulatory glycolipids for polarization of immune responses. J. Biomed. Sci. 24, 22 (2017).

64. Wun, K. S. et al. A minimal binding footprint on $\mathrm{CD} 1 \mathrm{~d}$-glycolipid is a basis for selection of the unique human NKT TCR. J. Exp. Med. 205, 939-949 (2008).

65. Joyce, S. et al. Adaptability of the semi-invariant natural killer T-cell receptor towards structurally diverse CD1 d-restricted ligands. EMBO J. 28 3579-3590 (2009).

66. Wu, D. et al. Bacterial glycolipids and analogs as antigens for CD1d-restricted NKT cells. Proc. Nat Acad. Sci. USA 102, 1351-1356 (2005).

67. Xing, G. W. et al. Synthesis and human NKT cell stimulating properties of 3-O-sulfo- $\alpha / \beta$ galactosylceramides. Bioorg. Med. Chem. 13, 2907-2916 (2005).

68. Zhang, W. et al. Introduction of aromatic group on $4^{\prime}-\mathrm{OH}$ of $\alpha$-GalCer manipulated NKT cell cytokine production. Bioorg. Med. Chem. 19, 2767-2776 (2011).

69. Janssens, J. et al. Efficient divergent synthesis of new immunostimulant 4"-modified $\alpha$-galactosylceramide analogues. ACS Med. Chem. Lett. 8, 642-647 (2017).

70. Janssens, J. et al. 4"-O-Alkylated $\alpha$-galactosylceramide analogues as iNKT-cell antigens: synthetic, biological, and structural studies. ChemMedChem 14, 147-168 (2019).

71. Pauwels, N. et al. Divergent synthetic approach to $6^{\prime \prime}$-modified $\alpha$-GalCer analogues. Org. Biomol. Chem. 9, 8413-8421 (2011).

72. Trappeniers, M. et al. 6'-Derivatised $\alpha$-GalCer analogues capable of inducing strong CD1d-mediated Th1-biased NKT cell responses in mice. J. Am. Chem. Soc. 130, 16468-16469 (2008)

73. Aspeslagh, S. et al. Galactose-modified iNKT cell agonists stabilized by an induced fit of CD 1d prevent tumour metastasis. EMBO J. 30, 2294-2305 (2011)

74. Aspeslagh, S. et al. Enhanced TCR footprint by a nove glycolipid increases NKT-dependent tumor protection. J. Immunol. 191, 2916-2925 (2013)

75. Prigozy, T. I. et al. Glycolipid antigen processing for presentation by CD 1d molecules. Science 291 , 664-667 (2001). 
76. Ma, W. et al. Synthesis and biological activities of amino acids functionalized $\alpha$-GalCer analogues. Bioorg. Med. Chem. 28, 115141 (2020).

77. Zhou, X. T. et al. Synthesis and NKT cell stimulating properties of fluorophore- and biotin-appended 6"-amino-6"-deoxy-galactosylceramides. Org. Lett. 4, 1267-1270 (2002)

78. Cheng, J. M. H. et al. An improved synthesis of dansylated $\alpha$-galactosylceramide and its use as a fluorescent probe for the monitoring of glycolipid uptake by cells. Carbohydr. Res. 346, 914-926 (2011)

79. Tashiro, T. et al. RCAl-56, a carbocyclic analogue of KRN7000: its synthesis and potent activity for natura killer (NK) T cells to preferentially produce interferon- $\gamma$. Tetrahedron Lett. 48, 3343-3347 (2007).

80. Jervis, P. J. et al. New CD 1d agonists: synthesis and biological activity of 6"-triazole-substituted $\alpha$-galactosy ceramides. Bioorg. Med. Chem. Lett. 22, 4348-4352 (2012).

81. Hung, J. T. et al. Design and synthesis of galactose6-OH-modified $\alpha$-galactosyl ceramide analogues with Th2-biased immune responses. RSC Adv. 4 47341-47356 (2014).

82. Franck, R. W. \& Tsuji, M. $\alpha$-C-galactosylceramides: synthesis and immunology. Acc. Chem. Res. 39, 692-701 (2006)

83. Li, X., Chen, G., Garcia-Navarro, R., Franck, R. W. \& Tsuji, M. Identification of C-glycoside analogues that display a potent biological activity against murine and human invariant natural killer T cells. Immunology 127, 216-225 (2009).

84. Dere, R. T. \& Zhu, X. The first synthesis of a thioglycoside analogue of the immunostimulant KRN7000. Org. Lett. 10, 4641-4644 (2008).

85. Hogan, A. E. et al. Activation of human invariant natural killer T cells with a thioglycoside analogue of a-galactosylceramide. Clin. Immunol. 140 196-207 (2011)

86. Goff, R. D. et al. Effects of lipid chain lengths in $\alpha$-galactosylceramides on cytokine release by natural killer T cells. J. Am. Chem. Soc. 126, 13602-13603 (2004).

87. Miyamoto, K., Miyake, S. \& Yamamura, T. A synthetic glycolipid prevents autoimmune encephalomyelitis by inducing TH2 bias of natural killer T cells. Nature $\mathbf{4 1 3}$ 531-534 (2001).

This study describes a synthetic glycolipid $(\mathrm{OCH})$ that elicited a $\mathrm{T}_{\mathrm{H}}$ 2-biased immune response through predominant production of IL-4 by NKT cells, ultimately leading to suppression of autoimmune encephalomyelitis in mice.

88. Yu, K. O A et al. Modulation of CD1d-restricted NKT cell responses by using $\mathrm{N}$-acyl variants of a-galactosylceramides. Proc. Natl Acad. Sci. USA 102 3383-3388 (2005)

89. Lee, T. et al. Synthesis and evaluation of 1,2,3-triazole containing analogues of the immunostimulant a-GalCer. J. Med. Chem. 50, 585-589 (2007).

90. Inuki, S. et al. Isolated polar amino acid residues modulate lipid binding in the large hydrophobic cavity of CD1d. ACS Chem. Biol. 11, 3132-3139 (2016).

91. Inuki, S. et al. Potent Th2 cytokine bias of natural killer T cell by CD $1 \mathrm{~d}$ glycolipid ligands: anchoring effect of polar groups in the lipid component. Angew. Chem. Int. Ed. Engl. 57, 9655-9659 (2018).

92. Kim, H., Song, H., Park, J. G., Lee, D. S. \& Park, S. B. Development of $\alpha$-GalCer analogues with an a-fluorocarbonyl moiety as Th2-selective ligands of CD1d. ACS Med. Chem. Lett. 10, 773-779 (2019).

93. Kishi, J. et al. Design and discovery of covalent $\alpha$-GalCer derivatives as potent CD1d ligands. ACS Chem. Biol. 15, 353-359 (2020).

94. Wu, D. et al. Design of natural killer T cell activators: structure and function of a microbial glycosphingolipid bound to mouse CD1d. Proc. Natl Acad. Sci. USA 103, 3972-3977 (2006)

95. Fujio, M. et al. Structure-based discovery of glycolipids for CD 1d-mediated NKT cell activation: tuning the adjuvant versus immunosuppression activity. J. Am. Chem. Soc. 128, 9022-9023 (2006).

96. Li, X. et al. Design of a potent CD1d-binding NKT cell ligand as a vaccine adjuvant. Proc. Natl Acad. Sci. USA 107, 13010-13015 (2010).

97. Feng, H. et al. A glycolipid adjuvant, 7DW8-5, enhances the protective immune response to the current split influenza vaccine in mice. Front. Microbiol. 10, 2157 (2019)

98. Lin, K. H. et al. In vivo protection provided by a synthetic new alpha-galactosyl ceramide analog against bacterial and viral infections in murine models. Antimicrob. Agents Chemother. 54, 4129-4136 (2010).
99. Huang, Y.-L. et al. Carbohydrate-based vaccines with a glycolipid adjuvant for breast cancer. Proc. Natl Acad. Sci. USA 110, 2517-2522 (2013).

100. Sidobre, S. et al. The T cell antigen receptor expressed by $V_{\alpha} 14 \mathrm{i}$ NKT cells has a unique mode of glycosphingolipid antigen recognition. Proc. Natl Acad. Sci. USA 101, 12254-12259 (2004).

101. Leung, L. et al. Synthesis and in vivo evaluation of 4-deoxy-4,4-difluoro-KRN7000. Org. Lett. 10, 4433-4436 (2008).

102. Baek, D. J. et al. The 3-deoxy analogue of $\alpha$-GalCer disclosing the role of the 4-hydroxyl group for CD $1 \mathrm{~d}$ mediated NKT cell activation. ACS Med. Chem. Lett. 2 , 544-548 (2011)

103. Hunault, J. et al. 3-Fluoro- and 3,3-difluoro3,4-dideoxy-KRN7000 analogues as new potent immunostimulator agents: total synthesis and biologica evaluation in human invariant natural killer T cells and mice. J. Med. Chem. 55, 1227-1241 (2012)

104. Golten, S. et al. 3,4-Dideoxy-3,3,4,4-tetrafluoroand 4-OH epimeric 3-deoxy-3,3-difluoro- $\alpha$-GalCer analogues: synthesis and biological evaluation on human iNKT cells stimulation. Eur. J. Med. Chem 178, 195-213 (2019).

105. Chennamadhavuni, D. et al. Dual modifications of a-galactosylceramide synergize to promote activation of human invariant natural killer T cells and stimulate anti-tumor immunity. Cell Chem. Biol. 25, 571-584 (2018).

106. Hwang, Y. S., Yim, J., Song, H. \& Park, S. B. Improved Th 17 selectivity of $\alpha$-galactosylceramide via noncovalent interactions with diether moiety. ACS Med Chem Lett 10, 720-725 (2019).

107. Trauner, D. et al. Optical control of cytokine production using photoswitchable galactosylceramides. Chem. Eur. J. 26, 4476-4479 (2019).

108. Sakai, T., Naidenko, O. V., lijima, H., Kronenberg, M. $\&$ Koezuka, Y. Syntheses of biotinylated $\alpha$ galactosylceramides and their effects on the immune system and CD1 molecules. J. Med. Chem. 42, 1836-1841 (1999).

109. Sakai, T., Ehara, H. \& Koezuka, Y. Synthesis of NBDa-galactosylceramide and its immunologic properties. Org. Lett. 1, 359-362 (1999)

110. Veerapen, $\mathbf{N}$. et al. Photoactivable glycolipid antigens generate stable conjugates with CD 1d for invariant natural killer T cell activation. Bioconjug. Chem. 29 , 3161-3173 (2018)

111. Cavallari, M. et al. A semisynthetic carbohydrate-lipid vaccine that protects against $S$. pneumoniae in mice. Nat. Chem. Biol. 10, 950-956 (2014).

This work reports an $\alpha$-GalCer-S. pneumoniae polysaccharide conjugate vaccine that elicited protective antigen-specific antibodies in mice.

112. Götze, S. et al. Synthesis, liposomal formulation, and immunological evaluation of a minimalistic carbohydrate- $\alpha-\mathrm{GalCer}$ vaccine candidate. J. Med. Chem. 61, 4918-4927 (2018)

113. Yin, X. G. et al. IgG antibody response elicited by a fully synthetic two-component carbohydrate-based cancer vaccine candidate with a-galactosylceramide as built-in adjuvant. Org. Lett. 19, 456-459 (2017)

114. Chen, P.-G. et al. Fully synthetic invariant NKT celldependent self-adjuvanting antitumor vaccines eliciting potent immune response in mice. Mol. Pharm. 17, 417-425 (2020)

115. Compton, B. J. et al. Synthesis and activity of 6"-deoxy-6"-thio- $\alpha$-GalCer and peptide conjugates. Org. Lett. 17, 5954-5957 (2015).

116. Anderson, R. J. et al. A self-adjuvanting vaccine induces cytotoxic $T$ lymphocytes that suppress allergy. Nat. Chem. Biol. 10, 943-949 (2014).

This papers reports the covalent conjugation of an allergen-derived peptide to an $\alpha$-GalCer-based proadjuvant to provide a self-adjuvanting vaccine that induced a peptide-specific cytotoxic $T$ lymphocyte response able to reduce inflammation in a mouse model.

117. Anderson, R. J. et al. NKT cell-dependent glycolipidpeptide vaccines with potent anti-tumour activity. Chem. Sci. 6, 5120-5127 (2015)

118. Anderson, R. J. et al. Augmenting influenza-specific $\mathrm{T}$ cell memory generation with a natural killer $\mathrm{T}$ celldependent glycolipid-peptide vaccine. ACS Chem. Biol. 12, 2898-2905 (2017)

119. Fujii, S. I., Shimizu, K., Smith, C., Bonifaz, L. \& Steinman, R. M. Activation of natural killer T cells by $\alpha$-galactosylceramide rapidly induces the full maturation of dendritic cells in vivo and thereby acts as an adjuvant for combined CD4 and CD8 T cell immunity to a coadministered protein. J. Exp. Med. 198, 267-279 (2003).
120. Van Kaer, L., Parekh, V. V. \& Wu, L. Invariant NK $T$ cells: potential for immunotherapeutic targeting with glycolipid antigens. Immunotherapy 3, 59-75 (2011).

121. Bai, L. et al. Natural killer T (NKT)-B-cell interactions promote prolonged antibody responses and long-term memory to pneumococcal capsular polysaccharides. Proc. Natl Acad. Sci. USA 110, 16097-16102 (2013).

122. Carreño, L. J., Saavedra-Ávila, N. A. \& Porcelli, S. A Synthetic glycolipid activators of natural killer T cells as immunotherapeutic agents. Clin. Transl. Immunol. 5, e69 (2016).

123. Carreño, L. J., Kharkwal, S. S. \& Porcelli, S. A. Optimizing NKT cell ligands as vaccine adjuvants. Immunotherapy 6, 309-320 (2014).

124. Arora, P. et al. A rapid fluorescence-based assay for classification of iNKT cell activating glycolipids. J. Am. Chem. Soc. 133, 5198-5201 (2011).

125. Raetz, C. R. H. \& Whitfield, C. Lipopolysaccharide endotoxins. Annu. Rev. Biochem. 71, 635-700 (2002)

126. Simpson, B. W. \& Trent, M. S. Pushing the envelope: LPS modifications and their consequences. Nat. Rev. Microbiol. 17, 403-416 (2019).

127. Mazgaeen, L. \& Gurung, P. Recent advances in lipopolysaccharide recognition systems. Int. J. Mol. Sci. 21, 379 (2020).

128. Kieser, K. J. \& Kagan, J. C. Multi-receptor detection of individual bacterial products by the innate immune system. Nat. Rev. Immunol. 17, 376-390 (2017). This review describes several pattern recognition receptors that recognize bacterial cell wall components such as lipopolysaccharide and discusses the various signalling pathways they induce.

129. Silipo, A. \& Molinaro, A. in Bacterial Lipopolysaccharides (eds Knirel, Y. A. \& Valvano, M. A.) 1-20 (Springer, 2011).

130. Bohannon, J. K., Hernandez, A., Enkhbaatar, P. $\&$ Adams, W. L. The immunobiology of TLR4 agonists: from endotoxin tolerance to immunoadjuvants. Shock 40, 451-462 (2013)

131. Needham, B. D. \& Trent, M. S. Fortifying the barrier: the impact of lipid A remodelling on bacterial pathogenesis. Nat. Rev. Microbiol. 11, 467-481 (2013).

132. Molinaro, A. et al. Chemistry of lipid A: at the heart of innate immunity. Chem. Eur. J. 21, 500-519 (2015). This review summarizes the structural features, physico-chemical properties and structure-activity relationships of lipopolysaccharides.

133. Cochet, F. $\&$ Peri, F. The role of carbohydrates in the lipopolysaccharide (LPS)/toll-like receptor 4 (TLR4) signalling. Int. J. Mol. Sci. 18, 2318 (2017).

134. Gao, J. \& Guo, Z. Progress in the synthesis and biological evaluation of lipid $A$ and its derivatives. Med. Res. Rev. 38, 556-601 (2018)

135. Zhang, Y., Gaekwad, J., Wolfert, M. A. \& Boons, G.-J. Modulation of innate immune responses with synthetic lipid A derivatives. J. Am. Chem. Soc. 129, 5200-5216 (2007).

136. Takada, H., Kotani, S. \& Lüderitz, O. Structural requirements of lipid $\mathrm{A}$ for endotoxicity and other biological activities. Crit. Rev. Microbiol. 16, 477-523 (1989).

137. Rietschel, E. T. et al. Bacterial endotoxin: molecular relationships of structure to activity and function. FASEB J. 8, 217-225 (1994).

138. Persing, D. H. et al. Taking toll: lipid A mimetics as adjuvants and immunomodulators. Trends Microbiol. 10, s32-s37 (2002)

139. Gaekwad, J. et al. Differential induction of innate immune responses by synthetic lipid A derivatives. J. Biol. Chem. 285, 29375-29386 (2010).

140. Liu, W.-C., Oikawa, M., Fukase, K., Suda, Y. \& Kusumoto, S. A divergent synthesis of lipid $A$ and its chemically stable unnatural analogues. Bull. Chem. Soc. Jpn. 72, 1377-1385 (1999).

141. Mochizuki, T. et al. Synthesis and biological activities of lipid A-type pyrancarboxylic acid derivatives. Carbohydr. Res. 324, 225-230 (2000).

142. Akamatsu, M. et al. Synthesis of lipid A monosaccharide analogues containing acidic amino acid: exploring the structural basis for the endotoxic and antagonistic activities. Bioorg. Med. Chem. 14, 6759-6777 (2006).

143. Matsuura, M., Kiso, M. \& Hasegawa, A. Activity of monosaccharide lipid $A$ analogues in human monocytic cells as agonists or antagonists of bacterial lipopolysaccharide. Infect. Immun. 67, 6286-6292 (1999).

144. Lam C et al SDZ MRL 953, a novel immunostimulatory monosaccharidic lipid $A$ analog with an improved therapeutic window in experimental sepsis. Antimicrob. Agents Chemother. 35, 500-505 (1991). 
145. Tamai, R. et al. Cell activation by monosaccharide lipid A analogues utilizing Toll-like receptor 4. Immunology 110, 66-72 (2003)

146. Johnson, D. A. et al. Synthesis and biological evaluation of a new class of vaccine adjuvants: aminoalkyl glucosaminide 4-phosphates (AGPs). Bioorg. Med. Chem. Lett. 9, 2273-2278 (1999).

147. Johnson, D. A. Synthetic TLR4-active glycolipids as vaccine adjuvants and stand-alone immunotherapeutics. Curr. Top. Med. Chem. 8, 64-79 (2008).

148. D'Alonzo, D. et al. A semisynthetic approach to new immunoadjuvant candidates: site-selective chemical manipulation of Escherichia coli monophosphoryl lipid A. Chem. Eur. J. 22, 11053-11063 (2016).

149. Adanitsch, F. et al. Synthetic glycan-based TLR4 agonists targeting caspase-4/11 for the development of adjuvants and immunotherapeutics. Chem. Sci. 9 , 3957-3963 (2018)

This work reports picomolar affinity synthetic lipid A mimetics as potentially safer adjuvant candidate inducing controllable TLR4 signalling without triggering caspase 11 protease activity.

150. Qureshi, N., Mascagni, P., Ribi, E. \& Takayama, K. Monophosphoryl lipid A obtained from lipopolysaccharides of Salmonella minnesota R595. Purification of the dimethyl derivative by high performance liquid chromatography and complete structural determination. J. Biol. Chem. 260 5271-5278 (1985)

151. Garçon, N., Chomez, P. \& Van Mechelen, M. GlaxoSmithKline adjuvant systems in vaccines: concepts, achievements and perspectives. Expert Rev. Vaccines 6, 723-739 (2007)

152. Kundi, M. New hepatitis B vaccine formulated with an improved adjuvant system. Expert Rev. Vaccines 6, 133-140 (2007)

153. Garçon, N. \& Van Mechelen, M. Recent clinical experience with vaccines using MPL- and QS-21containing adjuvant systems. Expert Rev. Vaccines 10 471-486 (2011)

154. Cluff, C. W. in Lipid A in Cancer Therapy. Advances in Experimental Medicine and Biology Vol. 667 (ed. Jeannin, J.-F.) 111-123 (Springer, 2009).

155. Fox, C. B., Carter, D., Kramer, R. M., Beckmann, A. M \& Reed, S. G. in Immunopotentiators in Modern Vaccines: Second Edition (eds Schijns, V. E. J. C. \& O'Hagan, D. T.) 105-127 (Academic, 2017).

156. Myers, K. R. et al. Preparation and characterization of biologically active 6'-O-(6-aminocaproyl)-4'-Omonophosphoryl lipid $\mathrm{A}$ and its conjugated derivative. Bioconjug. Chem. 3, 540-548 (1992)

157. Myers, K. R et al. Monophosphoryl lipid A behaves as a T-cell-independent type 1 carrier for hapten-specific antibody responses in mice. Infect. Immun. 63 168-174 (1995)

158. Ziaco, M. et al. Development of clickable monophosphoryl lipid A derivatives toward semisynthetic conjugates with tumor-associated carbohydrate antigens. J. Med. Chem. 60, 9757-9768 (2017)

159. Wang, O., Xue, J. \& Guo, Z. Synthesis of a monophosphoryl lipid A derivative and its conjugation to a modified form of a tumor-associated carbohydrate antigen GM3. Chem. Commun. https://doi.org/10.1039/ b907351E (2009).

160. Tang, S., Wang, Q. \& Guo, Z. Synthesis of a monophosphoryl derivative of Escherichia coli lipid A and its efficient coupling to a tumor-associated carbohydrate antigen. Chem. Eur. J. 16, 1319-1325 (2010)

161. Liao, G., Zhou, Z., Suryawanshi, S., Mondal, M. A. $\&$ Guo, Z. Fully synthetic self-adjuvanting $\alpha-2,9$ oligosialic acid based conjugate vaccines against group C meningitis. ACS Cent. Sci. 2, 210-218 (2016).

162. Wang, O., Zhou, Z., Tang, S. \& Guo, Z. Carbohydratemonophosphoryl lipid A conjugates are fully synthetic self-adjuvanting cancer vaccines eliciting robust immune responses in the mouse. ACS Chem. Biol. 7 235-240 (2012).

163. Zhou, Z., Liao, G., Mandal, S. S., Suryawanshi, S. $\&$ Guo, Z. A fully synthetic self-adjuvanting globo $\mathrm{H}$-based vaccine elicited strong $\mathrm{T}$ cell-mediated antitumor immunity. Chem. Sci. 6, 7112-7121 (2015) This paper reports the covalent conjugation of synthetic tumour-associated antigen globo-H and monophosphoryl lipid A to provide a selfadjuvanting vaccine able to elicit antigen-specific antibodies in mice.

164. Zhou, Z., Mandal, S. S., Liao, G., Guo, J. \& Guo, Z. Synthesis and evaluation of GM2-monophosphoryl lipid A conjugate as a fully synthetic self-adjuvant cancer vaccine. Sci. Rep. 7, 11403 (2017).
165. Park, B. S. \& Lee, J.-O. Recognition of lipopolysaccharide pattern by TLR 4 complexes. Exp. Mol. Med. 45, e66 (2013).

166. Lu, Y.-C., Yeh, W.-C. \& Ohashi, P. S. LPS/TLR4 signal transduction pathway. Cytokine 42, 145-151 (2008)

167. Park, B. S. et al. The structural basis of lipopolysaccharide recognition by the TLR4-MD-2 complex. Nature 458, 1191-1195 (2009).

168. Ohto, U., Fukase, K., Miyake, K. \& Shimizu, T Structural basis of species-specific endotoxin sensing by innate immune receptor TLR4/MD-2. Proc. Natl Acad. Sci. USA 109, 7421-7426 (2012).

169. Kawai, T. \& Akira, S. Toll-like receptors and their crosstalk with other innate receptors in infection and immunity. Immunity 34, 637-650 (2011)

170. Akira, S., Takeda, K. \& Kaisho, T. Toll-like receptors: critical proteins linking innate and acquired immunity. Nat. Immunol. 2, 675-680 (2001).

171. Kagan, J. C. et al. TRAM couples endocytosis of Tolllike receptor 4 to the induction of interferon- $\beta$. Nat. Immunol. 9, 361-368 (2008)

172. Karaghiosoff, M. et al. Central role for type I interferons and Tyk2 in lipopolysaccharide-induced endotoxin shock. Nat. Immunol. 4, 471-477 (2003).

173. Yamamoto, M. et al. Role of adaptor TRIF in the MyD88-independent toll-like receptor signaling pathway. Science 301, 640-643 (2003).

174. Shi, J. et al. Inflammatory caspases are innate immune receptors for intracellular LPS. Nature 514, 187-192 (2014).

175. Kayagaki, N. et al. Noncanonical inflammasome activation by intracellular LPS independent of TLR4 Science 341, 1246-1249 (2013). This study reports evidence of a TLR4-independen mechanism for innate immune recognition of LPS via caspase 11 activation by the non-canonical inflammasome.

176. Hagar, J. A., Powell, D. A., Aachoui, Y., Ernst, R. K \& Miao, E. A. Cytoplasmic LPS activates caspase-11 implications in TLR4-independent endotoxic shock. Science 341, 1250-1253 (2013).

177. Gurung, P. et al. Toll or interleukin-1 receptor (TIR) domain-containing adaptor inducing interferon- $\beta$ (TRIF)-mediated caspase-11 protease production integrates toll-like receptor 4 (TLR4) protein- and Nirp3 inflammasome-mediated host defense against enteropathogens. J. Biol. Chem. 287, 34474-34483 (2012).

178. Mata-Haro, V. et al. The vaccine adjuvan monophosphoryl lipid A as a TRIF-biased agonist of TLR4. Science 316, 1628-1632 (2007). This work shows that the low pro-inflammatory effects and reduced toxicity of monophosphoryl lipid A compared with lipid A is associated with a bias towards TRIF signalling over the MyD88 pathway.

179. Casella, C. R. \& Mitchell, T. C. Inefficient TLR4/MD-2 heterotetramerization by monophosphoryl lipid A. PLOS ONE 8, e62622 (2013).

180. Miyake, K. et al. The attenuated inflammation of MPL is due to the lack of CD14-dependent tight dimerization of the TLR4/MD2 complex at the plasma membrane. Int. Immunol. 26, 307-314 (2013).

181. Okemoto, K., Kawasaki, K., Hanada, K., Miura, M. \& Nishijima, M. A potent adjuvant monophosphory lipid $A$ triggers various immune responses, but not secretion of IL-1 $\beta$ or activation of caspase- 1 . J. Immunol 176, 1203-1208 (2006).

182. Salkowski, C. A., Detore, G. R. \& Vogel, S. N. Lipopolysaccharide and monophosphoryl lipid A differentially regulate interleukin-12, gamma interferon, and interleukin-10 mRNA production in murine macrophages. Infect. Immun. 65, 3239-3247 (1997).

183. De Becker, G. et al. The adjuvant monophosphoryl lipid $A$ increases the function of antigen-presenting cells. Int. Immunol. 12, 807-815 (2000).

184. Ismaili, J. et al. Monophosphoryl lipid A activates both human dendritic cells and T cells. J. Immunol. 168, 926-932 (2002)

185. Casella, C. R. \& Mitchell, T. C. Putting endotoxin to work for us: monophosphoryl lipid A as a safe and effective vaccine adjuvant. Cell. Mol. Life Sci. 65 3231-3240 (2008).

186. Cui, W. et al. TLR4 ligands lipopolysaccharide and monophosphoryl lipid A differentially regulate effector and memory $\mathrm{CD}^{+} \mathrm{T}$ cell differentiation. J. Immunol. 192, 4221-4232 (2014)

187. Kwissa, M., Nakaya, H. I., Oluoch, H. \& Pulendran, B. Distinct TLR adjuvants differentially stimulate systemi and local innate immune responses in nonhuman primates. Blood 119, 2044-2055 (2012).
188. Avci, F. Y. \& Kasper, D. L. How bacterial carbohydrates influence the adaptive immune system. Annu. Rev. Immunol. 28, 107-130 (2010).

This review highlights structural features, biologica roles and immunological significance of zwitterionic polysaccharides as immunomodulators, describing their processing and presentation by the MHC-II pathway, leading to $\mathrm{T}$ cell activation and adaptive immune responses.

189. Astronomo, R. D. \& Burton, D. R. Carbohydrate vaccines: developing sweet solutions to sticky situations? Nat. Rev. Drug Discov. 9, 308-324 (2010).

190. Mitchison, N. A. T-cell-B-cell cooperation. Nat. Rev. Immunol. 4, 308-312 (2004).

191. Tzianabos, A., Wang, J. Y. \& Kasper, D. L. Biological chemistry of immunomodulation by zwitterionic polysaccharides. Carbohydr. Res. 338, 2531-2538 (2003).

192. Wang, Y., Kalka-Moll, W. M., Roehrl, M. H. $\&$ Kasper, D. L. Structural basis of the abscessmodulating polysaccharide A2 from Bacteroides fragilis. Proc. Natl Acad. Sci. USA 97, 13478-13483 (2000).

193. Baumann, H., Tzianabos, A. O., Brisson, J. R., Kasper, D. L. \& Jennings, H. J. Structural elucidation of two capsular polysaccharides from one strain of Bacteroides fragilis using high-resolution NMR spectroscopy. Biochemistry 31, 4081-4089 (1992).

194. Lindberg, B., Lindqvist, B., Lönngren, J. \& Powell, D. A Structural studies of the capsular polysaccharide from Streptococcus pneumoniae type 1. Carbohydr. Res. 78, 111-117 (1980)

195. Jones, C. Revised structures for the capsular polysaccharides from Staphylococcus aureus Types 5 and 8, components of novel glycoconjugate vaccines. Carbohydr. Res. 340, 1097-1106 (2005).

196. Cobb, B. A. Wang O., Tzianabos, A. O. \& Kasper, D. L. Polysaccharide processing and presentation by the MHCII pathway. Cell 117, 677-687 (2004). This study describes the mechanism utilized by zwitterionic polysaccharides to activate $T$ cells, involving nitric-oxide-mediated processing and uptake into the MHC-II endocytic presentation pathway.

197. Choi, Y.-H., Roehrl, M. H., Kasper, D. L. \& Wang, J. Y. A unique structural pattern shared by T-cell-activating and abscess-regulating zwitterionic polysaccharides. Biochemistry 41, 15144-15151 (2002).

198. Kreisman, L. S. C., Friedman, J. H., Neaga, A $\Sigma$ Cobb, B. A. Structure and function relations with a T-cell-activating polysaccharide antigen using circular dichroism. Glycobiology 17, 46-55 (2007).

199. Tzianabos, A. O. Onderdonk, A. B., Rosner, B. Cisneros, R. L. \& Kasper, D. L. Structural features of polysaccharides that induce intra-abdominal abscesses. Science 262, 416-419 (1993).

200. Gallorini, S. et al. Introduction of zwitterionic motifs into bacterial polysaccharides generates TLR2 agonists able to activate APCs. J. Immunol. 179 , 8208-8215 (2007).

201. Gallorini, S. et al. Toll-like receptor 2 dependent immunogenicity of glycoconjugate vaccines containing chemically derived zwitterionic polysaccharides. Proc Natl Acad. Sci. USA 106, 17481-17486 (2009).

202. Zhang, Q., Overkleeft, H. S., van der Marel, G. A \& Codée, J. D. Synthetic zwitterionic polysaccharides. Curr. Opin. Chem. Biol. 40, 95-101 (2017).

203. Keith, D. J. \& Townsend, S. D. Total synthesis of the congested, bisphosphorylated Morganella morgani zwitterionic trisaccharide repeating unit. J. Am. Chem Soc. 141, 12939-12945 (2019).

204. Eradi, P. Ghosh, S. \& Andreana, P. R. Total synthesis of zwitterionic tetrasaccharide repeating unit from Bacteroides fragilis ATCC 25285/NCTC 9343 capsular polysaccharide PS A1 with alternating charges on adjacent monosaccharides. Org. Lett. 20, 4526-4530 (2018).

205. Nishat, S. \& Andreana, P. Entirely carbohydrate-based vaccines: an emerging field for specific and selective immune responses. Vaccines 4, 19 (2016).

206. De Silva, R. A., Wang, Q., Chidley, T., Appulage, D. K. $\propto$ Andreana, P. R. Immunological response from an entirely carbohydrate antigen: design of synthetic vaccines based on Tn-PS A1 conjugates. J. Am. Chem Soc. 131, 9622-9623 (2009). This paper reports the first zwitterionicpolysaccharide-based cancer vaccine conjugate consisting of PS A1 covalently linked to the tumourassociated carbohydrate Tn antigen that elicited antigen-specific antibodies in mice.

207. Shi, M., Kleski, K. A., Trabbic, K. R., Bourgault, J. P. $\&$ Andreana, P. R. Sialyl-Tn polysaccharide A1 as an 
entirely carbohydrate immunogen: synthesis and immunological evaluation. J. Am . Chem Soc 138, 14264-14272 (2016)

208. Trabbic, K. R., Bourgault, J.-P., Shi, M., Clark, M. $\&$ Andreana, P. R. Immunological evaluation of the entirely carbohydrate-based Thomsen-Friedenreich PS B conjugate. Org. Biomol. Chem. 14, 3350-3355 (2016).

209. De Silva, R. A. et al. The entirely carbohydrate immunogen Tn-PS A1 induces a cancer cell selective immune response and cytokine IL-17. Cancer Immunol. Immunother 61, 581-585 (2012).

210. Zhang, Q. et al. Synthetic, zwitterionic Sp1 oligosaccharides adopt a helical structure crucial for antibody interaction. ACS Cent. Sci. 5, 1407-1416 (2019).

This work describes the synthesis, tridimensional structural analysis and antibody binding studies of nonasaccharide and dodecasaccharide fragments of $\mathrm{Sp} 1$ as attractive mimics for generating anti-Sp1 vaccine candidates.

211. Tzianabos, A. O. et al. Bacterial pathogens induce abscess formation by $\mathrm{CD} 4{ }^{+} \mathrm{T}$-cell activation via the CD28-B7-2 costimulatory pathway. Infect. Immun. 68, 6650-6655 (2000)

212. Bloem, K. et al. Interaction of the capsular polysaccharide A from Bacteroides fragilis with DC-SIGN on human dendritic cells is necessary for its processing and presentation to T cells. Front. Immunol. 4, 103 (2013).

213. Mazmanian, S. K., Liu, C. H., Tzianabos, A. O. \& Kasper, D. L. An immunomodulatory molecule of symbiotic bacteria directs maturation of the host immune system. Cell 122, 107-118 (2005).

214. Cobb, B. A. \& Kasper, D. L. Characteristics of carbohydrate antigen binding to the presentation protein HLA-DR. Glycobiology 18, 707-718 (2008)

215. Wang, Q. et al. A bacterial carbohydrate links innate and adaptive responses through Toll-like receptor 2 . J. Exp. Med. 203, 2853-2863 (2006).

This paper reports the identification of TLR2 as a polysaccharide $A$ (PSA) receptor that plays a key role in initiating innate immunity by mediating activation of antigen-presenting cells and NF-кBdependent NO production, which, in turn, is critical for PSA processing and presentation, and T cell activation.

216. Mishra, A. K., Driessen, N. N., Appelmelk, B. J. \& Besra, G. S. Lipoarabinomannan and related glycoconjugates: structure, biogenesis and role in Mycobacterium tuberculosis physiology and hostpathogen interaction. FEMS Microbiol. Rev. 35 1126-1157 (2011).

217. Doz, E. et al. Acylation determines the toll-like receptor (TLR)-dependent positive versus TLR2-, mannose receptor-, and SIGNR1-independent negative regulation of pro-inflammatory cytokines by mycobacterial lipomannan. J. Biol. Chem. 282 26014-26025 (2007).

218. Mazurek, J. et al. Divergent effects of mycobacteria cell wall glycolipids on maturation and function of human monocyte-derived dendritic cells. PLOS ONE 7 e42515 (2012)

219. Ishikawa, E., Mori, D. \& Yamasaki, S. Recognition of mycobacterial lipids by immune receptors. Trends Immunol. 38, 66-76 (2017).

220. Yonekawa, A. et al. Dectin-2 is a direct receptor for mannose-capped lipoarabinomannan of mycobacteria. Immunity 41, 402-413 (2014).

221. Kang, P. B. et al. The human macrophage mannose receptor directs Mycobacterium tuberculosis lipoarabinomannan-mediated phagosome biogenesis. J. Exp. Med. 202, 987-999 (2005)

222. Tallieux, L. et al. DC-SIGN is the major Mycobacterium tuberculosis receptor on human dendritic cells. J. Exp. Med. 197, 121-127 (2003)

223. Turner, J. \& Torrelles, J. B. Mannose-capped lipoarabinomannan in Mycobacterium tuberculosis pathogenesis. Pathog. Dis. 76, fty026 (2018)

224. Källenius, G., Correia-Neves, M., Buteme, H., Hamasur, B. \& Svenson, S. B. Lipoarabinomannan, and its related glycolipids, induce divergent and opposing immune responses to Mycobacterium tuberculosis depending on structural diversity and experimental variations. Tuberculosis 96, 120-130 (2016).

225. Yuan, C. et al. Mycobacterium tuberculosis mannosecapped lipoarabinomannan induces IL-10-producing $B$ cells and hinders $C D 4^{+}$Th 1 immunity. iScience 11 13-30 (2019)

226. Ogawa, C., Liu, Y.-J. \& Kobayashi, K. S. Muramyl dipeptide and its derivatives: peptide adjuvant in immunological disorders and cancer therapy. Curr. Bioact. Compd. 7, 180-197 (2011).

227. Marina-García, N. et al. Clathrin- and dynamindependent endocytic pathway regulates muramyl dipeptide internalization and NOD2 activation. J. Immunol. 182, 4321-4327 (2009).

228. Schenk, M. et al. Human NOD2 recognizes structurally unique muramyl dipeptides from Mycobacterium leprae. Infect. Immun. 84, 2429-2438 (2016).

229. Azuma, I. et al. Adjuvant activity of carbohydrate analogs of $\mathrm{N}$-acetylmuramyl-L-alanyl-D-isoglutamine on the induction of delayed-type hypersensitivity to azobenzenearsonate- $\mathrm{N}$-acetyl-L-tyrosine in guinea pigs. Infect. Immun. 33, 834-839 (1981).

230. Marrakchi, H., Lanéelle, M.-A. \& Daffé, M. Mycolic acids: structures, biosynthesis, and beyond. Chem. Biol. 21, 67-85 (2014).

231. Ishikawa, E. et al. Direct recognition of the mycobacterial glycolipid, trehalose dimycolate, by C-type lectin mincle. J. Exp. Med. 206, 2879-2888 (2009).

232. Feinberg, $H$. et al. Mechanism for recognition of an unusual mycobacterial glycolipid by the macrophage receptor mincle. J. Biol. Chem. 288, 28457-28465 (2013).

233. Furukawa, A. et al. Structural analysis for glycolipid recognition by the $\mathrm{C}$-type lectins Mincle and $\mathrm{MCL}$. Proc. Natl Acad. Sci. USA 110, 17438-17443 (2013).

234. Miyake, Y. et al. C-type lectin MCL is an FcR receptor that mediates the adjuvanticity of mycobacterial cord factor. Immunity 38, 1050-1062 (2013).

235. Miyake, Y., Oh-hora, M. \& Yamasaki, S. C-type lectin receptor MCL facilitates Mincle expression and signaling through complex formation. J. Immunol. 194, 5366-5374 (2015).

236. Werninghaus, K. et al. Adjuvanticity of a synthetic cord factor analogue for subunit Mycobacterium tuberculosis vaccination requires FcR $\gamma$-Syk-Card9dependent innate immune activation. J. Exp. Med. 206, 89-97 (2009).

237. Schoenen, $\mathrm{H}$. et al. Cutting edge: Mincle is essential for recognition and adjuvanticity of the mycobacterial cord factor and its synthetic analog trehalosedibehenate. J. Immunol. 184, 2756-2760 (2010).

238. Agger, E. M. et al. Cationic liposomes formulated with synthetic mycobacterial cordfactor (CAF01): a versatile adjuvant for vaccines with different immunological requirements. PLOS ONE 3, e3116 (2008)

239. Lindenstrøm, T. et al. Tuberculosis subunit vaccination provides long-term protective immunity characterized by multifunctional CD4 memory T cells. J. Immunol. 182, 8047-8055 (2009).

240. Aagaard, C. et al. A multistage tuberculosis vaccine that confers efficient protection before and after exposure. Nat. Med. 17, 189-194 (2011).

241. Decout, A. et al. Rational design of adjuvants targeting the C-type lectin Mincle. Proc. Natl Acad. Sci. USA 114, 2675-2680 (2017).

242. Holzheimer, M. et al. Asymmetric total synthesis of mycobacterial diacyl trehaloses demonstrates a role for lipid structure in immunogenicity. ACS Chem. Biol. 15, 1835-1841 (2020).

243. Broaders, K. E., Cohen, J. A., Beaudette, T. T., Bachelder, E. M. \& Frechet, J. M. J. Acetalated dextran is a chemically and biologically tunable material for particulate immunotherapy. Proc. Natl Acad. Sci. USA 106, 5497-5502 (2009).

244. Chen, N. et al. Investigation of tunable acetalated dextran microparticle platform to optimize M2e-based influenza vaccine efficacy. J. Control. Release $\mathbf{2 8 9}$ 114-124 (2018).

245. Zhang, W., An, M., Xi, J. \& Liu, H. Targeting CpG adjuvant to lymph node via dextran conjugate enhances antitumor immunotherapy. Bioconjug. Chem. 28, 1993-2000 (2017).

246. Xu, X. et al. Carbohydrate-based adjuvants activate tumor-specific Th 1 and CD8 ${ }^{+}$T-cell responses and reduce the immunosuppressive activity of MDSCs. Cancer Lett. 440-441, 94-105 (2019)

247. Brown, G. D. \& Gordon, S. Fungal $\beta$-glucans and mammalian immunity. Immunity 19, 311-315 (2003).

248. Sato, M. et al. Direct binding of toll-like receptor 2 to zymosan, and zymosan-induced NF-kB activation and TNF- $\alpha$ secretion are down-regulated by lung collectin surfactant protein A. J. Immunol. 171, 417-425 (2003).

249. Dillon, S. et al. Yeast zymosan, a stimulus for TLR2 and dectin-1, induces regulatory antigen-presenting cells and immunological tolerance. J. Clin. Invest. 116 916-928 (2006).
250. Qi, C. et al. Differential pathways regulating innate and adaptive antitumor immune responses by particulate and soluble yeast-derived $\beta$-glucans. Blood 117, 6825-6836 (2011)

251. Novakovic, B. et al. $\beta$-Glucan reverses the epigenetic state of LPS-induced immunological tolerance. Cell 167, 1354-1368 (2016).

252. Jin, Y., Li, P. \& Wang, F. $\beta$-glucans as potential immunoadjuvants: a review on the adjuvanticity, structure-activity relationship and receptor recognition properties. Vaccine 36, 5235-5244 (2018).

253. Donadei, A. et al. Rational design of adjuvant for skin delivery: conjugation of synthetic $\beta$-glucan dectin- 1 agonist to protein antigen. Mol. Pharm. 12 , 1662-1672 (2015).

254. Wang, $H$. et al. $\beta$-Glucan as an immune activator and a carrier in the construction of a synthetic MUC1 vaccine. Chem. Commun. 55, 253-256 (2019).

255. Cooper, P. D. \& Petrovsky, N. Delta inulin: a novel, immunologically active, stable packing structure comprising $\beta$-D-[2 $\rightarrow 1]$ poly(fructo-furanosyl) $\alpha$-D-glucose polymers. Glycobiology 21, 595-606 (2011).

256. Petrovsky, N. \& Cooper, P. D. Advax ${ }^{\mathrm{Tm}}$, a novel microcrystalline polysaccharide particle engineered from delta inulin, provides robust adjuvant potency together with tolerability and safety. Vaccine 33 , 5920-5926 (2015).

257. Gordon, D., Kelley, P., Heinzel, S., Cooper, P. \& Petrovsky, N. Immunogenicity and safety of Advax ${ }^{\mathrm{TM}}$ a novel polysaccharide adjuvant based on delta inulin, when formulated with hepatitis B surface antigen: a randomized controlled phase 1 study. Vaccine 32 6469-6477 (2014).

258. Gordon, D. L. et al. Human phase 1 trial of low-dose inactivated seasonal influenza vaccine formulated with Advax $^{\mathrm{TM}}$ delta inulin adjuvant. Vaccine $34,3780-3786$ (2016).

259. Hayashi, M. et al. Advax, a delta inulin microparticle, potentiates in-built adjuvant property of co-administered vaccines. EBioMedicine 15 127-136 (2017).

260. Counoupas, C. et al. Delta inulin-based adjuvants promote the generation of polyfunctional $\mathrm{CD} 4^{+} \mathrm{T}$ cell responses and protection against Mycobacterium tuberculosis infection. Sci. Rep. 7, 8582 (2017).

261. Saade, F., Honda-Okubo, Y., Trec, S. \& Petrovsky, N. A novel hepatitis B vaccine containing Advax ${ }^{\mathrm{T}}$, a polysaccharide adjuvant derived from delta inulin, induces robust humoral and cellular immunity with minimal reactogenicity in preclinical testing. Vaccine 31, 1999-2007 (2013).

262. Sheng, K. C. et al. Mannan derivatives induce phenotypic and functional maturation of mouse dendritic cells. Immunology 118, 372-383 (2006)

263. Gadjeva, M., Takahashi, K. \& Thiel, S. Mannan-binding lectin - A soluble pattern recognition molecule. Mol. Immunol. 41, 113-121 (2004).

264. Lamkanfi, M., Malireddi, R. K. S. \& Kanneganti, T. D. Fungal zymosan and mannan activate the cryopyrin inflammasome. J. Biol. Chem. 284, 20574-20581 (2009).

265. Apostolopoulos, V., Pietersz, G. A., Loveland, B. E., Sandrin, M. S. \& McKenzie, I. F. Oxidative/reductive conjugation of mannan to antigen selects for T1 or T2 immune responses. Proc. Natl Acad. Sci. USA 92, 10128-10132 (1995)

266. Ahlên, G. et al. Mannosylated mucin-type immunoglobulin fusion proteins enhance antigen specific antibody and T lymphocyte responses. PLoS ONE 7, e46959 (2012).

267. Durăn-Lobato, M., Carrillo-Conde, B., Khairandish, Y. \& Peppas, N. A. Surface-modified P(HEMA-co-MAA) nanogel carriers for oral vaccine delivery: design, characterization, and in vitro targeting evaluation. Biomacromolecules 15, 2725-2734 (2014).

268. Sirvent, S. et al. Novel vaccines targeting dendritic cells by coupling allergoids to nonoxidized mannan enhance allergen uptake and induce functional regulatory $\mathrm{T}$ cells through programmed death ligand 1. J. Allergy Clin Immunol. 138, 558-567.e11 (2016).

269. Wu Y et al. Reversible mannosylation as a covalen binding adjuvant enhances immune responses for porcine circovirus type 2 vaccine. ACS Omega 3 , 17341-17347 (2018)

270. Karanikas, V. et al. Antibody and T cell responses of patients with adenocarcinoma immunized with mannan-MUC1 fusion protein. J. Clin. Invest. 100 2783-2792 (1997).

271. Apostolopoulos, V. et al. Pilot phase III immunotherapy study in early-stage breast cancer 
patients using oxidized mannan-MUC 1 [ISRCTN71711835]. Breast Cancer Res. 8, R27 (2006).

272. Vassilaros, S. et al. Up to 15-year clinical follow-up of a pilot phase III immunotherapy study in stage II breast cancer patients using oxidized mannan-MUC1. Immunotherapy 5, 1177-1182 (2013).

273. Aranaz, I. et al. Functional characterization of chitin and chitosan. Curr. Chem. Biol. 3, 203-230 (2009).

274. Zaharoff, D. A., Rogers, C. J., Hance, K. W., Schlom, J. $\Sigma$ Greiner, J. W. Chitosan solution enhances both humoral and cell-mediated immune responses to subcutaneous vaccination. Vaccine 25, 2085-2094 (2007).

275. Arca, H. Ç., Günbeyaz, M. \& Şenel, S. Chitosan-based systems for the delivery of vaccine antigens. Expert Rev. Vaccines 8, 937-953 (2009).

276. Li, X. et al. Chitin, chitosan, and glycated chitosan regulate immune responses: the novel adjuvants for cancer vaccine. Clin. Dev. Immunol. 2013, 387023 (2013)

277. Moran, H. B. T., Turley, J. L., Andersson, M. \& Lavelle, E. C. Immunomodulatory properties of chitosan polymers. Biomaterials 184, 1-9 (2018).

278. Bueter, C. L. et al. Chitosan but not chitin activates the inflammasome by a mechanism dependent upon phagocytosis. J. Biol. Chem. 286, 35447-35455 (2011).

279. Carroll, E. C. et al. The vaccine adjuvant chitosan promotes cellular immunity via DNA sensor cGAS STING-dependent induction of type I interferons. Immunity 44, 597-608 (2016)

280. Fong, D. et al. Lysosomal rupture induced by structurally distinct chitosans either promotes a type 1 IFN response or activates the inflammasome in macrophages. Biomaterials 129, 127-138 (2017).

281. Vasiliev, Y. M. Chitosan-based vaccine adjuvants: incomplete characterization complicates preclinical and clinical evaluation. Expert Rev. Vaccines 14 , 37-53 (2015).

282. Kaiko, G. E., Horvat, J. C., Beagley, K. W. $\&$ Hansbro, P. M. Immunological decision-making how does the immune system decide to mount a helper T-cell response? Immunology 123, 326-338 (2008).

283. Iwasaki, A. \& Medzhitov, R. Control of adaptive immunity by the innate immune system. Nat. Immunol. 16, 343-353 (2015)

284. Schijns, V. et al. Modulation of immune responses using adjuvants to facilitate therapeutic vaccination. Immunol. Rev. 296, 169-190 (2020).

This review discusses currently available adjuvants and their important role in directing antibody and cellular immune responses in the context of therapeutic vaccines.

285. Abbas, A. K., Murphy, K. M. \& Sher, A. Functional diversity of helper T lymphocytes. Nature 383, 787-793 (1996).

286. Su, X. et al. Interferon- $\gamma$ regulates cellular metabolism and mRNA translation to potentiate macrophage activation. Nat. Immunol. 16, 838-849 (2015).

287. Coffman, R. L., Lebman, D. A. \& Rothman, P. Mechanism and regulation of immunoglobulin isotype switching. Adv. Immunol. 54, 229-270 (1993).

288. Saenz, S. A., Noti, M. \& Artis, D. Innate immune cell populations function as initiators and effectors in Th2 cytokine responses. Trends Immunol. 31, 407-413 (2010).

289. Ruterbusch, M., Pruner, K. B., Shehata, L. \& Pepper, M In vivo $C D 4^{+} \mathrm{T}$ cell differentiation and function: revisiting the Th1/Th2 paradigm. Annu. Rev. Immunol. 38, 705-725 (2020).

290. Vignali, D. A. A., Collison, L. W. \& Workman, C. J. How regulatory T cells work. Nat. Rev. Immunol. 8 523-532 (2008).
291. Lucca, L. E. \& Dominguez-Villar, M. Modulation of regulatory $T$ cell function and stability by co-inhibitory receptors. Nat. Rev. Immunol. 20, 680-693 (2020).

\section{Acknowledgements}

Funding from the European Research Council (ERC2016-STG-716878 'ADJUV-ANT VACCINES' to A.F.-T.) and the Spanish Ministry of Science and Innovation (CTQ201787530-R, RYC-2015-17888 to A.F.-T.; Severo Ochoa accreditation SEV-2016-0644 to CIC bioGUNE) is gratefully acknowledged. The authors thank Juan Anguita (CIC bioGUNE) for proofreading the manuscript. A.F.-T. thanks Raquel Fernández for inspiration. C.P. dedicates this work to the memory of Maria Fassari (1959-2020).

\section{Author contributions}

C.P., R.F. and A.F.-T. researched data for the article and contributed to writing; C.P. and A.F.-T. contributed substantially to discussion of content; C.P. and A.F.-T. contributed to writing and reviewing/editing of the manuscript before submission.

\section{Competing interests}

A.F.-T. is co-inventor on patents and patent applications that include synthetic OS-21 variants mentioned in this work. C.P. and R.F. declare no competing interests.

\section{Peer review information}

Nature Reviews Chemistry thanks S. van Kasteren, Z. Guo and the other, anonymous, reviewer(s) for their contribution to the peer review of this work.

\section{Publisher's note}

Springer Nature remains neutral with regard to jurisdictional claims in published maps and institutional affiliations.

(c) Springer Nature Limited 2021 